\title{
Review
}

\section{Oxidative Stress: Emerging Mitochondrial and Cellular Themes and Variations in Neuronal Injury}

\author{
Gavin C. Higgins ${ }^{\mathrm{a}}$, Philip M. Beart ${ }^{\mathrm{b}, \mathrm{c}, *}$, Yea Seul Shin ${ }^{\mathrm{b}, \mathrm{d}}$, Minghui Jessica Chen ${ }^{\mathrm{e}}$, \\ Nam Sang Cheung ${ }^{\mathrm{e}}$ and Phillip Nagley ${ }^{\mathrm{a}}$ \\ ${ }^{a}$ Department of Biochemistry and Molecular Biology, Monash University, Clayton, VIC, Australia \\ ${ }^{\mathrm{b}}$ Florey Neuroscience Institutes, University of Melbourne, Parkville, VIC, Australia \\ ${ }^{\mathrm{c}}$ Department of Pharmacology, University of Melbourne, Parkville, VIC, Australia \\ ${ }^{\mathrm{d}}$ Centre for Neuroscience, University of Melbourne, Parkville, VIC, Australia \\ ${ }^{\mathrm{e}}$ Menzies Research Institute, University of Tasmania, Hobart, Tasmania, Australia
}

Accepted 16 April 2010

\begin{abstract}
Oxidative stress plays a central role in neuronal injury and cell death in acute and chronic pathological conditions. The cellular responses to oxidative stress embrace changes in mitochondria and other organelles, notably endoplasmic reticulum, and can lead to a number of cell death paradigms, which cover a spectrum from apoptosis to necrosis and include autophagy. In Alzheimer's disease, and other pathologies including Parkinson's disease, protein aggregation provides further cellular stresses that can initiate or feed into the pathways to cell death engendered by oxidative stress. Specific attention is paid here to mitochondrial dysfunction and programmed cell death, and the diverse modes of cell death mediated by mitochondria under oxidative stress. Novel insights into cellular responses to neuronal oxidative stress from a range of different stressors can be gained by detailed transcriptomics analyses. Such studies at the cellular level provide the key for understanding the molecular and cellular pathways whereby neurons respond to oxidative stress and undergo injury and death. These considerations underpin the development of detailed knowledge in more complex integrated systems, up to the intact human bearing the neuropathology, facilitating therapeutic advances.
\end{abstract}

Keywords: Apoptosis, autophagy, mitochondria, necrosis, neurodegeneration, neurons, oxidative stress, programmed cell death

\section{INTRODUCTION}

ROS, RONS, and cellular defenses

Onset of oxidative stress is a prominent feature of neuronal injury. Oxidative stress is caused by the chem-

\footnotetext{
${ }^{*}$ Correspondence to: Philip M. Beart, Florey Neuroscience Institutes, University of Melbourne, Parkville, VIC 3010, Australia. Tel.: +61 38344 1955; Fax: +61 39347 0446; E-mail: phil.beart@ florey.edu.au.
}

ical imbalance between production of reactive oxygen species (ROS) production and breakdown of the chemically reactive species by reducing agents and enzymes, collectively known as antioxidants. Over-abundance of ROS has been found during neuronal development, as well as in neuropathological conditions, such as Parkinson's disease (PD) [1] and Alzheimer's disease (AD) [2] where oxidative stress occurs chronically, and in more acute settings such as during ischemic reperfusion injury following the onset of stroke [3]. Neurons are considered highly susceptible to oxidative stress 
due to their being intrinsically ill-equipped to defend against an increase in ROS, due to low levels of antioxidants relative to those in other mammalian cell types [4]. Nonetheless, glial cells, including astrocytes, centrally play a supplementary role in antioxidant defense of neurons. It is pertinent at the outset to provide a brief overview of ROS and reactive oxygen and nitrogen species (RONS), their properties and cellular defenses.

ROS are a family of highly reactive small molecules that contain oxygen; the ROS family includes both oxygen radicals and non-radical derivatives of $\mathrm{O}_{2}$ [5]. Free radicals are defined as atoms, molecules or ions that have unpaired electrons, resulting in an unstable species [6]. Mitochondria are one of the main intracellular sources of ROS, produced during oxidative phosphorylation within all mammalian cells [7]. The most common form of ROS released by mitochondria, superoxide $\left(\mathrm{O}_{2}^{-}\right)$is generated through the escape of single electrons during oxidative phosphorylation (from complexes I, II and III), which interact with $\mathrm{O}_{2}$ [8]. $\mathrm{O}_{2}^{-}$can subsequently be transformed into other forms of ROS, such as hydrogen peroxide $\left(\mathrm{H}_{2} \mathrm{O}_{2}\right)$ by the enzyme superoxide dismutase (SOD), or can react with nitric oxide (NO) and be converted into peroxynitrite $\left(\mathrm{ONO}_{2}^{-}\right)[6,9]$. As "reactive oxygen species" both NO and $\mathrm{ONO}_{2}^{-}$are encompassed within a larger collective known as RONS, a term often used in this field. Furthermore, $\mathrm{H}_{2} \mathrm{O}_{2}$ in turn can also be transformed into the highly reactive hydroxy radical $(\mathrm{OH})$ via Fenton reactions involving transition metal ions [9]. Indeed $\mathrm{OH}$ is so reactive with a variety of targets including DNA, RNA, lipids, and proteins that it is considered the most potent of all ROS, albeit having the shortest half life [10]. Nonetheless, each of these ROS mentioned above is capable of causing irreversible injury to cells, by oxidatively damaging the nucleic acid, protein, and lipid targets, on which a variety of chemical modifications result. This chemical damage impairs function and leads to cellular debilitation and possibly premature death.

To regulate and counter the damaging effects associated with ROS, mammalian cells have antioxidant defense mechanisms. Antioxidants that act chemically are reducing agents that prevent the oxidation of other molecules that are present within the cell by ROS. There are also enzymes that catalyze antioxidant reactions; the key enzymes that make up the antioxidant defense of most mammalian cells are SOD, catalase, and glutathione peroxidase (Gpx), the latter two of which convert $\mathrm{H}_{2} \mathrm{O}_{2}$ to $\mathrm{H}_{2} \mathrm{O}$ [9]. In neurons it has been shown that SOD and Gpx are expressed in higher quantities than catalase. However, the low levels of catalase enhance the risk of over-exposure to $\mathrm{H}_{2} \mathrm{O}_{2}$ and other ROS that derive from it [11-13]. Other antioxidant molecules, some of which can act in a more direct chemical mode to reduce oxidative stress and which are present in neurons, include vitamin E, melatonin, and glutathione (GSH). The last-named can act alone chemically or as a cofactor to Gpx [14,15]. In vivo, GSH and its precursors are made available to neurons by astrocytes which have a more efficient peroxide detoxification system then their neuronal counterparts $[16$, $17]$.

We will now focus here on aspects germane to the scope of this review, namely emerging mitochondrial cellular themes of oxidative stress and neuronal injury. For a more detailed discussion of the role of RONS in the brain and the pathophysiology of particular neurodegenerative diseases, the reader is referred to an excellent review [10]. There are two further points worthy of note.

First, at moderate or "physiological" levels, RONS are critical players in normal cellular behavior when tightly regulated [18]. It is only when the levels of RONS are excessive in terms of normal cellular requirements that molecular damage and cellular debilitation can result. Moreover, a paucity of RONS can cause cellular defects, particularly where individual RONS are involved in cellular signaling [18]. These generalities apply to neuronal systems as for most other cell types.

Second, as mentioned, sources of RONS have been recognized as intracellular, with mitochondria as one of the main sources. But mitochondria are in this respect not alone in that endoplasmic reticulum (ER) enzymes such as P450 can also generate ROS. Cells may also be exposed to external sources of RONS. These may be from direct exposure to excessive oxygen, as in ischemia-reperfusion injuries, or to excessive neurotransmitters or oxidation products thereof. Yet another source of external ROS under neuropathological conditions are phagocytes that are the main source of oxidants in vivo [19]. Amongst these in the brain are particularly the microglia, which account for the largest population of phagocytes closely related to the central nervous system. Microglia are normally maintained in a quiescent state and in low cellular abundance under physiological conditions, but they quickly propagate upon induction by neuropathological events that result in an inflammatory response [20]. 


\section{Broad relationships between ROS generation and neuronal injury in $A D$ and $P D$}

The escape of single electrons from the mitochondrial electron transport chain (ETC), mainly from complexes I and III, is a natural by-product of oxidative phosphorylation [21], and these processes are likely to be modified by overall bioenergetics and compromised mitochondrial biology [22,23]. However, in chronic neurodegenerative diseases, for instance AD and PD, the mitochondrial respiratory function is thought to be disrupted by potentially aggregating proteins namely the amyloid- $\beta(\mathrm{A} \beta)$ fragment of amyloid- $\beta$ protein precursor $(\mathrm{A} \beta \mathrm{PP})$, and $\alpha$-synuclein $(\alpha \mathrm{SN})$, respectively (see review [24]), exacerbating the escape of electrons and consequently elevating oxidative stress within neurons. In the case of more acute injury such as stroke, oxidative stress ensues when the supply of oxygen to the brain is restricted, limiting oxidative phosphorylation and causing an increase in the "escape of electrons" from mitochondria, in the form of reduced and partially reduced intermediates. When blood flow is restored during ischemic reperfusion, the newly abundant oxygen reacts with the pools of these reduced molecules, resulting in enhanced oxidative stress due to production of abundant ROS. In each of these neuropathological settings evidence has been reported of oxidative damage in post-mortem brains. However, it remains uncertain whether neuronal cell death in each instance is a direct result of oxidative stress or whether it is a non-consequential by-product of the diseased state. Nonetheless, cell death mechanisms triggered by RONS have become the focal point of many studies due to the destructive nature of these chemically reactive molecules.

Neurons, like all cells, possess inbuilt capacities to handle physiological levels of RONS by endogenous antioxidant defense systems. However, when the balance is tilted towards the net production of RONS, tissue injury results in many diseases, including agerelated neuropathologies $[25,26]$. Here the brain differs from most other organs in that relative to SODs and catalase, GSH is a key antioxidant with both cytoplasmic and mitochondrial GSH pools having the potential to buffer oxidative stress [10]. Disruption of the homeostasis of the GSH system promotes oxidative injury sensitizing neurons to oxidative stressors and to $\mathrm{A} \beta$-toxicity during $\mathrm{AD}[27,28]$. Indeed, there are age-related declines in GSH and cytochrome c (cyt c); dietary N-acetyl cysteine, which elevates GSH and cysteine, provides beneficial effects reversing these changes, decreasing markers of oxidative stress in the brain and improving cognitive deficits [26]. However, the debate continues about the efficacy of anti-oxidant therapies in neurodegenerative conditions, with one such apparently successful example being with coenzyme $\mathrm{Q}_{10}$ in early Parkinsonism [29].

Neurons respond to damage by either dying, which can be in the form of programmed cell death (PCD) (or in extreme cases unregulated necrosis), or by remaining alive yet depleted of key neuronal functions, preventing their participation in neuronal networks required for cognitive or motor functions (as in $\mathrm{AD}$ or $\mathrm{PD}$, respectively). Here we focus on PCD, specifically oxidative stress and the involvement of mitochondria.

\section{Mitochondrial dysfunction and PCD}

In the context of the issues under consideration here, there are at least two upstream indices that might influence the patterns of recruitment of mitochondrial signaling to affect the resultant characteristics of PCD induced by oxidative stress, namely, mitochondrial membrane potential $\left(\Delta \psi_{m}\right)$ and cellular calcium [30]. Further, there is growing awareness that dysfunction of the ubiquitin proteasome system (UPS) and its ability to handle misfolded proteins (such as $\mathrm{A} \beta, \alpha \mathrm{SN}$, huntingtin (Htt), SOD1) might also exacerbate oxidative stress [31]. Upstream, the role of $\Delta \psi_{m}$ in neuronal injury has been one of continuing controversy, but its function has long been recognized to be dependent on the state of energization of the neuron and also can be influenced by dynamic fluxes in various intracellular calcium pools [32]. $\Delta \psi_{m}$ is also affected by transient variations in the physical interface between inner mitochondrial membrane (IMM) and outer mitochondrial membrane (OMM) that affect the dynamics of intermembrane space (IMS) proteins [33] and their potential release through the OMM after its permeabilization in death signaling. Thus, alterations in the $\mathrm{H}^{+}$gradient associated with the ETC may impact upon $\Delta \psi_{m}$ and the consequent mitochondrial permeability transition (MPT) with a likelihood of increasing the probability that a neuron will undergo PCD [30]. Secondly, cytosolic and mitochondrial calcium are important factors that, in concert with increased ROS production, may contribute to injury in $\mathrm{AD}$ and ischemic brain [34,35]. Indeed, there is a clear mechanistic link between ROS generation and elevated mitochondrial calcium [36], which may be independent of $\Delta \psi_{m}$ influenced by the cellular context [37]. Recent insights into the involvement of the ER in PCD indicate that while its 
role as a major cellular store of calcium has been long recognized, mitochondria and ER are closely linked functionally, perhaps via calcium micro-domains [38], wherein multiple ER-based mechanisms may give rise to $\mathrm{PCD}$ [30]. Both $\mathrm{A} \beta \mathrm{PP}$ and $\mathrm{A} \beta$ accumulate in mitochondrial membranes in neurons such that there are now recognized to be multiple possible alterations of mitochondrial (e.g., calcium, MPT) and ER dynamics that could determine the final route to PCD [39-41].

Neuronal cell death induced by oxidative stress has previously been reported as apoptotic in some systems, although acute and an intense oxidative stress commonly leads to unregulated necrosis. The involvement of caspases has been central to defining under which of these two broad cell death pathways a dying neuron can be categorized. In this early basic view, apoptosis is a cell death pathway regulated by the activation of caspases, while necrosis is unregulated and independent of caspase activity. This basic view of cell death brought on by RONS has been challenged by the discovery of alternative forms of caspase-independent PCD, such as autophagy and programmed necrosis (encompassing other more exotic terms such as necroptosis and parthanatos, reflecting subtypes of programmed necrosis) [30].

\section{Significance of cellular investigations}

Even though evidence of oxidative stress has been ubiquitously detected in post-mortem brains of many neurological disorders through its consequential effects, the significance of its engagement during neuronal death progression remains unclear. As such, experimental models become an attractive avenue for deciphering the pathological mechanisms upstream and/or downstream of oxidative stress. As oxidative stress has achieved the status of a "central dogma" in numerous neuropathological conditions, novel insights into the signaling transduction pathways modulated upon its occurrence would form a foundation for the identification of potential biological targets useful in the area of therapeutic management.

Understanding the cellular response to oxidative stress is therefore critical to deciphering the impact of multiple factors in relating cellular dysfunction to disease pathology. Figure 1 depicts a general schema for the primary players in the cellular responses to oxidative stress as discussed above, and illustrates the relationship between ROS/RONS and key cellular organelles. These include mitochondria and ER, which together with intracellular calcium, modulate the cel- lular responses leading to death. Of specific relevance to many neurodegenerative diseases, protein aggregation can act as a further precipitating or exacerbating factor in the catastrophic responses into which cells are pushed. The specific manifestations of death are multiplexed, and cover many characteristic outcomes, encompassing a spectrum including apoptosis, autophagic death, programmed necrosis (and, under highly "traumatic" conditions, unregulated necrosis) (Fig. 1).

In this review, we amplify three relatively focused aspects based on this general schema. First, we discuss the mitochondrial respiratory chain and its relationship to oxidative stress and consequent cell death. This is done with reference to pathologies including AD, PD and Huntington's disease (HD). Second, we elaborate the ways in which specific modes of cell death are induced by oxidative stress under different conditions. Third, we outline a novel approach being applied to dissect the cellular responses to a range of stressors that elicit oxidative stress, in terms of the alterations in gene expression that can help us understand just what neuronal cells do when confronted with acute oxidative stress relevant to disease. These considerations provide an overview of contemporary approaches to understanding how oxidative stress can injure and kill neurons in the context of diseases such as AD and PD.

\section{MITOCHONDRIAL RESPIRATORY COMPLEXES, OXIDATIVE DAMAGE AND PCD}

Much information about the involvement of the respiratory chain in ROS generation and neuronal injury has been gathered from a plethora of well executed investigations in isolated neuronal mitochondria. Studies have allowed considerable mechanistic insights into the physiological and pathological aspects of respiratory chain function (e.g., forward/reverse electron transfer, oxygen consumption, $\Delta \psi_{m}$ ). However, an important caveat remains that such data have been collected in a milieu devoid of determinants of PCD up-stream and down-stream of mitochondria, including various molecular species influencing the biology of mitochondrial ROS (e.g., NO) and factors involving other cellular compartments likely to determine the final profile of PCD [30]. As a consequence, much of this early ground-breaking work has been overtaken by the latest advances in our understanding of PCD [30]. In this view, stressors induce injury across an insult-dependent apoptosis-necrosis continuum [42], such that death out- 


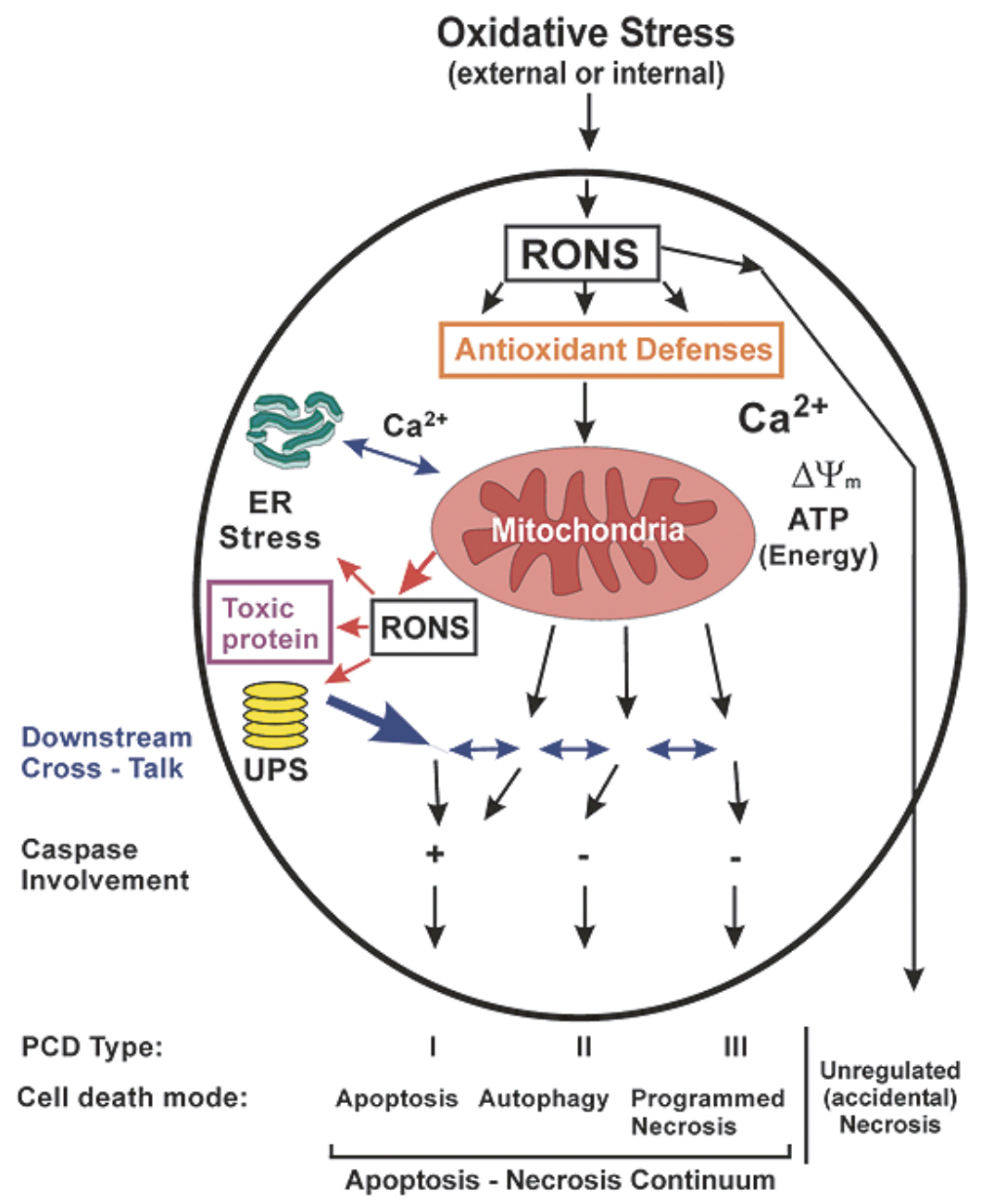

Fig. 1. Cellular responses to oxidative stress leading to the various types of PCD in neurons. This schematic emphasizes the main players in the cellular response to oxidative stress, once antioxidant defenses are overcome. The source of RONS can be external (as discussed in text) or internal i.e., generated from mitochondria (as shown in the figure, with red arrows indicating some targets). In chronic neurodegenerative disorders such as AD, PD, HD, and ALS, toxic proteins contribute to, and synergize, with the effects of the oxidative stressors. Toxic proteins compromise the biology of ER, UPS and mitochondria (not shown here for clarity). The net effect of various factors including ER stress, toxic proteins and UPS dysfunction on downstream pathways is shown by wide blue arrow. The outcomes (set out in lower half of the figure) occur as various forms of cell death, mostly PCD, representing various elements within the apoptosis-necrosis continuum [30]. The details of the various components of this schematic are discussed in the text.

comes are multifaceted within a holistic framework of interplay between multiple injury mechanisms, often operating in parallel [43-45] (Fig. 1).

Our ongoing work employing primary cultured neurons (cerebellar granule cells, [46]) has explored the pharmacological inhibition of the respiratory chain, to provide an approach considered to mimic the loss of electron flux, under pathological conditions. This entails a re-examination of the actions of selective inhibitors of complexes I-IV, thus placing this work in a contemporary context ([47] and Shin YS and Beart PM, unpublished observations). Rotenone, 3- nitroproprionic acid (3NP), antimycin A and potassium cyanide, which are respectively inhibitors of complexes, I, II, III and IV, all produced time-dependent and insult-dependent reductions in neuronal viability. The rank order of potency was antimycin $\mathrm{A}>$ rotenone $>$ $3 \mathrm{NP}>$ potassium cyanide; interestingly, 3NP was the only insult not able to effect a total reduction in cell viability. All insults produced a slow pattern of neuronal injury across the apoptosis-necrosis continuum, involving an absence of early swelling, shrinkage of somata and a loss of neuritic networks; the canonical nature of such injury patterns is currently under inves- 
tigation. Recent work in hippocampal cell lines confirms that in intact cells, inhibitors of complexes I-III increase intracellular ROS levels [48].

Given that oxidative damage is reported to occur widely in AD brain, oxidative stress may be the earliest change that contributes to the pathobiology of AD. The apparent more extensive damage due to oxidative stress, rather than occurrence of plaques/tangles as such, and the early generation of free radicals in animal models of $\mathrm{AD}$, together focus attention of the sites of ROS production, mitochondrial signaling and downstream recruitment of PCD. In this light, mitochondrial $\mathrm{A} \beta$ has been detected before extensive extracellular $\mathrm{A} \beta$ deposits and the diminished activity of complexes III and IV (see reviews [49,50]). There is an enormous literature addressing all perspectives of oxidative stress in postmortem $\mathrm{AD}$ tissue and animal models and this is updated in other parts of this volume. Recent advances include the description of an imbalance in iron homeostasis, which might drive metal ion-associated Fenton reactions, and hence which could be an important initiator of oxidative damage in the early pathophysiology of $\mathrm{AD}$ [51].

The rapidly expanding evidence for roles of both $\mathrm{A} \beta \mathrm{PP}$ and $\mathrm{A} \beta$, once accumulated in mitochondrial membranes of neurons to potentially affect various aspects of mitochondrial-ER interactions and thus to influence the recruitment of various routes to demise by PCD, extend previous information on PCD in AD [5255]. There is involvement of ER stress-related and autophagic mechanisms, which neurons activate as "inbuilt" defense responses via early phases of both the unfolded protein response (UPR) and chaperonemediated autophagy. As proposed in our model [30], should the threat to a neuronal population progress beyond a minor crisis involving bioenergetics and misfolded protein (i.e., $\mathrm{A} \beta$ ), then UPR would switch to its destructive mode and autophagy would be unable to clear the increased load of $\mathrm{A} \beta$ species with the UPS expected to become increasingly dysfunctional. Building on early observations on autophagosomes in postmortem AD brain [56], there is now a rapidly expanding literature on autophagic mechanisms in primary neurons exposed to $\mathrm{A} \beta$ and in animal AD models [57-60].

In light of issues underlying ROS generation and the sites of dysfunction of the ETC likely to contribute to neurodegeneration, we have undertaken a targeted analysis of the roles of complexes I-IV in neuronal injury. Complex I activity has consistently been shown to be reduced in postmortem nigral tissue of PD patients and the complex I inhibitor rotenone stimulates
ROS production in isolated mitochondria, although this perception may be too simplistic [61]. Firstly, the absence of complex I activity seems not to protect dopaminergic neurons and the actions of rotenone and 1-methyl-4-phenylpyridinium $\left(\mathrm{MPP}^{+}\right)$might be independent of complex I inhibition [62]. Both toxins produce PCD of nigral dopaminergic neurons involving non-classical recruitment of the intrinsic mitochondrial pathway, since there is preferential redistribution of the IMS protein apoptosis inducing factor (AIF) [63,64], which although associated with complex I, has both pro-apoptotic and anti-apoptotic actions. Recent work in isolated mitochondria from the Harlequin mouse questions whether complex I is in fact a major contributor to ROS production [65]. There remain many unanswered questions here, and indeed these may reflect uncertainties surrounding the Harlequin mouse model where the phenotype has been linked recently to human mitochondrial-complex I-deficiency syndromes and not loss of AIF [66].

Indeed the significant association with complex I of $\alpha \mathrm{SN}$ in postmortem tissue from PD patients may be of relevance to the pathophysiology of parkinsonism [61]. In vivo modest accumulation of $\alpha \mathrm{SN}$ induces the protective phases of the UPR and autophagy [67]. Overall, while there are significant methodological issues here relevant to isolated mitochondria versus intact cells, and cell lines relative to primary neurons, the dopaminergic neurotoxins rotenone and $\mathrm{MPP}^{+}$do have various actions eliciting PCD (see review [30]), and accumulation of $\alpha \mathrm{SN}$ in its various forms may predispose neurons to injury by ER stress and/or autophagy [68]. In light of this recent reappraisal of complex I and oxidative stress, new insights into the redox actions of paraquat, an environmental poison known to produce parkinsonism, are of some interest. Whilst not a complex I inhibitor (unlike $\mathrm{MPP}^{+}$and rotenone), paraquat and related herbicides engender oxidative stress via complex I and other mitochondrial respiratory enzymes complexes, where they induce ROS production (including superoxide) by redox cycling [69]. This induction of ROS by paraquat occurs in both isolated mitochondria and primary neurons [70]. However, it has been recently questioned whether complex I is a critical target for the triad of drugs (rotenone, $\mathrm{MPP}^{+}$or paraquat) because cells from mice lacking a key complex I gene did not show resistance to cell death after being treated with these agents [71].

By contrast, there is much less evidence for the involvement of complex II in oxidative stress and neurodegeneration. Deficits of complex II have been docu- 
mented in the striatum of symptomatic HD patients $[72$, 73], but impairments of mitochondrial respiratory activity are generally considered secondary to events in HD pathology [72]. By the far the most attention has centered on the pathophysiological sequence of events that follow the use of the complex II inhibitor $3 \mathrm{NP}$ in vivo or in culture models where it has been used to model aspects of the pathology of HD [74]. The reversible complex II inhibitor malonate induces a similar pattern of injury to 3NP by a mechanism involving exacerbation of excitotoxicity. Our data in cultured striatal GABAergic neurons reveal that $3 \mathrm{NP}$ induces a profile of PCD more consistent with programmed necrosis with early redistribution of AIF involving activation of both calpain and caspase-3 [75]. Mutant Htt has reported effects, both NMDA-mediated and calcium-mediated, on $\Delta \psi_{m}$. These responses can alter the sensitivity to, and nature of, 3NP-induced PCD (see review [30]). The $\mathrm{N}$-terminal fragment of mutant $\mathrm{Htt}$ induces deficits in complex II in striatal neurons (considered to parallel the GABAergic neurons lost in HD) and over-expression of succinate dehydrogenase subunits reverses this effect [76]. Mutant Htt also seems to associate with mitochondria to affect intramitochondrial calcium influx and mitochondrial DNA [77]. Such interactions are likely to underlie reports of ER stress in the Htt knock-in mouse and post-mortem HD tissue (see review [30]), and to be relevant to the intracellular redistribution of $\mathrm{Htt}$ and its role in autophagy [78].

Concerning the roles of complexes III and IV in oxidative stress and neurodegeneration, there is a large body of findings relevant to deficits of complexes III and IV in $\mathrm{AD}$, which are considered secondary to direct effects of $\mathrm{A} \beta$ on mitochondrial function and to precede AD pathology (see reviews $[49,50]$ ). Complex IV seems to regularly exhibit reduced activity in various neuropathologies, including HD [72,76], amyotrophic lateral sclerosis (ALS) [79] and multiple sclerosis [80], although the evidence is quite sparse in both the latter pathologies. With increased focus on the mitochondrial abnormalities in acute and chronic neurodegenerative conditions, we can expect new insights into the role of mitochondrial respiratory complexes in oxidative injury.

\section{DIVERSE MODES OF CELL DEATH MEDIATED BY MITOCHONDRIA UNDER OXIDATIVE STRESS}

Oxidative stress is thought to be a key activator of cell death in many neuropathological settings. The cell death pathways invoked in response to oxidative stress have generally been accepted as being either apoptotic (i.e., caspase-dependent and programmed tightly) under chronic oxidative stress or necrotic (i.e., caspaseindependent and unregulated) under more acute oxidative insults. However, it is now emerging that alternate routes to death exist, with PCD also manifesting itself in caspase-independent forms such as autophagy and programmed necrosis [30] (see also Fig. 1). It is evident that these multiple PCD pathways are active in neurons and that they play an integral role in bringing about cellular demise when elicited by elevated oxidative stress. Adding further complexity to this is the prospect that, within a given population of neurons, more than one PCD pathway can be activated simultaneously in response to a singular insult (Fig. 2). Within dying neurons in individuals bearing chronic neuronal diseases such as PD, AD and ALS, and in more acute neuronal injuries such as cerebral ischemia-reperfusion injury, mitochondrial dysfunction and elevated oxidative stress have been linked to the cause of the pathological outcome in these settings. However, studies at a cellular level of the PCD mechanisms at play in these affected neurons in the intact organism are very difficult and exacting. Therefore, basic cellular models that recapitulate disease phenotypes are vital to facilitate better understanding of the orchestration of PCD through mitochondria and oxidative stress.

\section{Chronic oxidative stress and PCD: apoptosis and autophagy}

In chronic neurodegenerative diseases, elevations in oxidative stress levels are thought to be progressive and, at relatively low concentrations, result in a slow accumulation of cellular oxidative damage. Under these conditions neurons have a tendency to undergo apoptosis (Fig. 2B). Due to mitochondrial dysfunction being the main source of RONS under these circumstances, it is considered to be the most susceptible organelle to oxidative insult, resulting in the intrinsic apoptotic pathway being invoked.

In neuronal cell models simulating chronic oxidative stress conditions, RONS have been shown to initiate apoptosis by activating $\mathrm{p} 53$, which in turn upregulates the BH3-only protein PUMA [81]. Once upregulated, PUMA translocates to the mitochondria where it activates Bax $[81,82]$. In non-neuronal cells another p53regulated $\mathrm{BH} 3$-only protein Noxa has been reported to compete for Bak at the mitochondrial level, displacing it from Mcl-1 and Bcl-xL during cell death [83]. 


\section{A. Diversity of neuronal death}

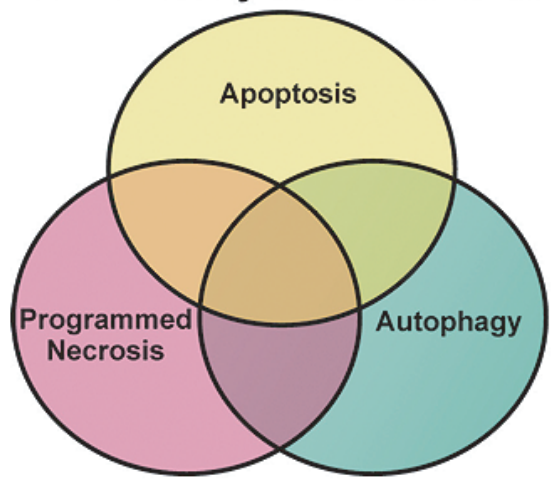

\section{B. Chronic ROS, low intensity}
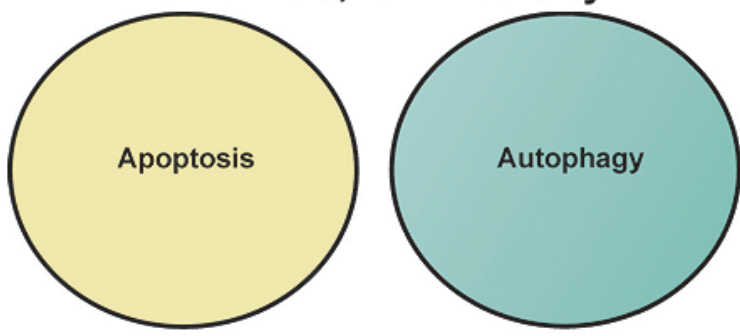

C. Acute ROS, moderate intensity

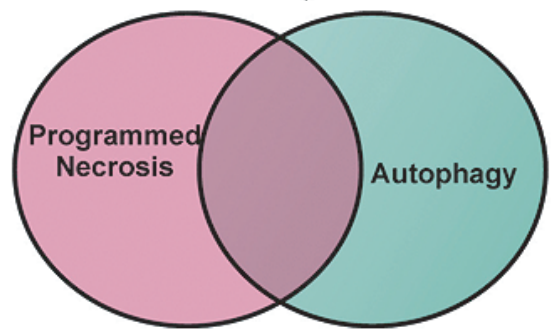

Fig. 2. Cell death outcomes in neurons stressed under particular conditions. A) Overall diversity of the main death pathways and their partial overlap. B) Under chronic oxidative stress, at relatively low intensity, neurons tend to undergo apoptosis, while autophagy proceeds it is not necessarily liked to the death outcome, but rather is a cellular defense mechanism. This condition can be replicated by treatment of cells with standard apoptosis inducers such as staurosporine (Higgins GC and Nagley P, unpublished observations) C) Under acute oxidative stress at moderate intensity cells undergo programmed necrosis [87], as well as autophagy that in part contributes to the death outcome. Note that the autophagic pathways in conditions B and C may not be mechanistically identical. Under acute oxidative stress at high intensity, cells are likely to undergo unregulated necrosis (not shown here).

Though, the role of Noxa in neuronal cell death appears to be less significant than PUMA. It has been shown that neurons are capable of increasing Noxa mRNA expression levels during times of oxidative stress and DNA damage [82,84]. In SK-N-SH human neuroblas- tomas cells exposure to the oxidative stressor paraquat which produces pathological features similar to those of PD (see above), activates cells to produces high levels of Noxa and Bak [85]. Knockdown of these proteins via short interfering RNA (siRNA) protects these cells from paraquat treatment. Translocation of Bax and Bak to the OMM initiates outer mitochondrial membrane permeabilization (OMMP), resulting in the redistribution of pro-apoptotic factors from the mitochondrial IMS, such as cyt c, Smac/DIABLO and HtrA2/Omi which are essential for the activation of downstream effector caspase-3 and caspase-7, ultimately leading to neuronal cell death [86-88].

An alternative PCD pathway has recently been recognized to occur under chronic oxidative stress conditions, known as autophagic cell death or PCD-Type II (where apoptosis is PCD-type I). Autophagy is the process whereby molecules and organelles undergo lysosomal clearance/degradation in order to help maintain cellular homeostasis. The autophagic process can manifest itself via several different pathways (see review [89]). However, the process most commonly associated with mitochondria and cell death is macroautophagy (referred to as "autophagy" herein), which will be the focus of discussion here. Autophagy involves the formation of a double membrane vesicle known as an autophagosome, which sequesters and engulfs organelles or molecules and transports them to lysosomes for degradation. Due to the post-mitotic nature of neurons, there is thought to be a heightened emphasis on autophagy to maintain homeostasis of functional organelles, such as mitochondria [90]. The prominence of autophagy in neurons can be attributed to the lack of cellular division, which contributes to the build-up of dysfunctional mitochondria and protein aggregates (i.e., $\mathrm{A} \beta$ or $\alpha \mathrm{SN}$ ) in $\mathrm{AD}$ and $\mathrm{PD}$ respectively. The concept that mitochondria are central to the cell death decision process also has relevance to autophagic cell death, specifically in relation to the process of mitochondrial autophagy or mitophagy (see review [91]). However, the exact mechanism and teleology underlying this process remains unclear. For example, it is not well understood how mitophagy is able to selectively target mitochondria, and the cellular role needs clarification, i.e., whether mitophagy is beneficial or detrimental. Interesting emerging aspects relating to neurodegeneration include the possible relationships of mitochondrial structure (e.g., their fission and fusion) and their motility, in terms of their susceptibility to mitophagy and participation in cell death signaling [92, 93]. 
Nonetheless, some insight has been gained into the role of mitophagy in neurons and other mammalian cell types. Depolarized mitochondria or those associated with Bax, for example, have been suggested to have a propensity to be cleared via mitophagy in the absence of caspase activation during cell death (see review [91]). In rat cortical neurons, the process of mitophagy has been suggested, with increased observations of autophagy associated with oxidative damage to mitochondria [94]. In the context of neuronal cell death, there are at least two routes involving autophagy which can come into play. The first is when the autophagic process is insufficient to deal with toxic protein aggregates, as possibly occurs in AD and PD (see review [95]). The second involves the up-regulation of autophagy that is a direct contributor to cell death as in PCD-Type II. Adding further intricacy to this paradigm has been the recent discovery of cross-talk between autophagy and the apoptotic pathways (see review [30]), as illustrated schematically in Fig. 1 above.

$\mathrm{A} \beta$ is generally accepted as the main initiator of oxidative stress, mitochondrial dysfunction and apoptosis induction in AD. However, little is known about the exact cell death mechanisms that are invoked during the pathophysiology of AD. Many previous studies have focused on the activation of caspases both upstream and downstream of mitochondria and the involvement of Bcl-2 family members in the cell death cascade during AD (see review [96]). However, the classic morphological hallmarks of apoptosis, i.e. nuclear condensation/fragmentation, cell shrinkage and blebbing, are not generally seen in post mortem studies done on AD patients. Furthermore, it has been shown that in vivo downstream effector caspases $-3,-6$ and -7 are not up-regulated in response to the onset of AD [97]. These findings indicate that possibly other non-apoptotic pathways may also invoke PCD. Under AD conditions, autophagic activity has been shown to be elevated, with mitochondria one of the primary targets for degradation [98]. Moreover, another study undertaken in differentiated neuroblastomas cells has shown that elevations of oxidative stress can trigger autophagy, leading to intralysosomal accumulation of $\mathrm{A} \beta$ [99]. The resulting intralysosomal accumulation of $\mathrm{A} \beta$ subsequently causes lysosomal membrane permeabilization, which in turn promotes apoptosis (as monitored by changes in nuclear morphology and Bax mobilization to mitochondria) [100]. These studies hint at possible cross-talk between apoptosis and autophagy pathways, which warrant further investigation to help establish the cell death mechanisms of AD.
While much evidence supports oxidative stress being produced by deficits in complex I functionality, concomitantly with the formation of Lewy bodies, in dopaminergic neurons of PD patients (both sporadic and familiar forms), mutations in other proteins have also been implicated in familial forms of PD. Some of these proteins are thought to influence ROS generation and ultimately regulate the cell death pathways, via mitochondria. Mutations in nuclear-encoded PD proteins PTEN-induced kinase 1 (PINK1) and Parkin have been implicated as causes of mitochondrial dysfunction [101]. PINK1 and Parkin are both involved in the same pathway regulating mitochondrial morphology. PINK1 is a kinase that is believed to be imported and activated within mitochondria, although its exact location within this organelle remains controversial (see review [101]). Conversely, Parkin exhibits E3 ubiquitin ligase activity in vitro and catalyzes various types of ubiquitinylation, which may link it to the UPS. While essentially a cytosolic protein, it has also been shown to associate with the OMM [102].

Both PINK1 and Parkin knockout mice have reduced mitochondrial respiratory function, as well as evidence of elevated oxidative stress levels [103-105]. Mutations in PINK1 have been shown to cause morphological abnormalities in mitochondria, as well as increasing sensitivity to ROS insult and subsequent cell death [103]. Overexpression of PINK1 in neuronal cell lines has been shown to decrease apoptosis, with reductions in cyt $\mathrm{c}$ redistribution and downstream caspase activation [106]. PINK1 phosphorylates tumor necrosis factor receptor-associated protein (TRAP1, also known as Hsp75) under oxidative stress, which prevents apoptosis [107]. Furthermore, there is genetic evidence supporting the interaction of PINK1 and HtrA2/Omi [108], although this still remains controversial [109,110]. It has been demonstrated that HtrA2/Omi is phosphorylated in a PINK-dependent manner, which is protective against parkinsonian neurotoxins 6-hydroxdopamine (6-OHDA) and rotenone, preventing apoptosis [109]. Similarly, Parkin has also been shown to prevent cell death. Parkin has been shown to be recruited to dysfunctional mitochondria in an ATP-independent, voltagedependent manner promoting mitophagy [104] and preventing intrinsic apoptosis, as shown in differentiated PC12 cells treated with ceramide [102]. This antiapoptotic effect is also abolished by PD-associated mutations within the Parkin gene [102].

The process of mitophagy has also been linked to $\mathrm{PD}$, with evidence for the clearance of mitochondria that contain Parkin. The relocalization of Parkin from 
the cytoplasm to the mitochondria was followed by the disappearance of mitochondrial markers concomitantly with the appearance of numerous lysosomes within cells [111]. Further evidence of a link between mitophagy in PD was seen through loss of function of PINK1. Stable knockdown of PINK1 in SH-SY5Y neuroblastomas resulted in elevated oxidative stress, increased mitochondrial fission and turnover via autophagy [103]. This outcome was restored by reintroducing PINK1. Moreover, recruitment of Parkin to mitochondria has been shown to be dependent on PINK1 [112], raising the possibility that these proteins are responsible for targeting dysfunctional mitochondria for degradation [113]. Mutations to either PINK1 or Parkin may therefore result in an accumulation of dysfunctional mitochondria and ultimately cell death.

Mutations of another PD related gene, DJ-1, lead to a rare form of familial PD. DJ-1 partially localizes to the mitochondria and acts as an antioxidant or redox sensor preventing cell death [114]. DJ-1 over-expression has been reported to protect cells from oxidative stress associated insults $[114,115]$. It has also been reported to upregulate GSH synthesis when oxidative stress levels are elevated [116]. Likewise, DJ-1 knockdown by siRNA in Neuro2a neuronal cell lines lead to increased cell death triggered by oxidative stress [117]. There has also been recent evidence to suggest that DJ-1 expression is increased in human AD brains, in which oxidative stress is considered to be a major contributor to the pathology of the disease [118].

\section{Acute oxidative stress: autophagy and programmed necrosis}

In more acute neuronal injuries, such as stroke and subsequent cerebral ischemic reperfusion injury, high doses of RONS were previously thought to invoke unregulated necrosis at the centre of the infarction, with apoptosis occurring at the penumbra [119]. However, it is now apparent that caspase-independent cell death in these settings may indeed be PCD, representing alternative pathways such as programmed necrosis or autophagic cell death. Evidence is now emerging that under acute insults multiple cell death pathways can be invoked and that cross-talk may exist between them. Moreover, it is also becoming apparent that different cell death pathways can be elicited by different types and doses of oxidative stress. The induction of autophagy during oxidative insult has been well documented in other cell types (see review [120]). NGFdeprived sympathetic neurons can accumulate mito- chondrial ROS which results in lipid peroxidation and the loss of IMM lipid cardiolipin and ultimately autophagic cell death [121]. However these limited neuronal studies involving oxidative stress have infrequently explored autophagic cell death as an alternative death mechanism to apoptosis. Similarly, limited studies have been undertaken in neurons to ascertain the involvement of programmed necrosis in response to acute oxidative stress.

We have recently shown that under acute oxidative stress conditions provided by exogenous $\mathrm{H}_{2} \mathrm{O}_{2}$, primary cortical neurons from C57 Black $6 \mathrm{~J}$ mice are deficient in downstream caspase activity, and are capable of undergoing programmed necrosis and autophagic cell death, as alternative PCD pathways [87]. First, PCD was shown to be dependent on Endonuclease $G$ (Endo G), a caspase-independent cell death protein that translocates from the mitochondria to the nucleus to invoke cell death via chromosomal DNA cleavage. Silencing of Endo G by siRNA inhibited cell death changes in nuclear morphology and arrested cell death. To further these studies, we have now shown that under $\mathrm{H}_{2} \mathrm{O}_{2}$ insult, autophagy activity is elevated as shown by autophagosome formation and conversion of microtubule-associated protein light chain 3 (LC3)-I to LC3-II (Higgins GC, Devenish RJ, Beart PM, Nagley P, unpublished data, submitted for publication). Furthermore this increase in autophagic activity correlated with the increase in loss of membrane integrity associated with cell death. Significantly in this work, autophagic cell death was confirmed by the inhibition of cell death with the autophagic inhibitor 3-methyladenine and by silencing the autophagic protein Atg7 with siRNA. Thus under these conditions programmed necrosis (PCD-Type III) and autophagy (PCD-Type II) proceed concurrently as death pathways (Fig. 2C).

A number of studies have reported the involvement of AIF as the main executioner, in the absence of caspase activity, following cerebral hypoxia-ischemia in primary neuronal cultures [46,122-124]. AIF is a mitochondrial IMS protein that is redistributed to the cytosol where it translocates to the nucleus to bring about DNA fragmentation within the nucleus. However, AIF has also been reported to act as an antioxidant via its oxidoreductase function, thus potentially causing conflicting actions to be invoked simultaneously. As mentioned above we have reported that under acute $\mathrm{H}_{2} \mathrm{O}_{2}$ insult, Endo $\mathrm{G}$ translocates to the nucleus where it also initiates DNA fragmentation and nuclear condensation [87]. Unlike AIF, Endo G has no oxidoreductase activity. We noted that possibly AIF has a primary 
function as an antioxidant under these conditions, resulting in the total dependence on Endo $\mathrm{G}$ to induce cell death under $\mathrm{H}_{2} \mathrm{O}_{2}$ treatment [87]. However, it also should be noted that under more acute conditions provided by xanthine/xanthine oxidase (in the presence of catalase) as a generator of the specific $\mathrm{ROS}, \mathrm{O}_{2}^{-}$, cell death still occurred even when Endo $\mathrm{G}$ was silenced. This demonstrated that under various oxidative insults different variants of the cell death pathways can be invoked (Higgins GC and Nagley P, unpublished data).

\section{NOVEL INSIGHTS INTO NEURONAL OXIDATIVE STRESS BASED ON MULTIPLE OXIDATIVE STRESSORS}

In order to further explore the differential response to various types of oxidative stress, prominent signaling pathways common to the transcriptomic profiles of two well-characterized stressors that induce cellular oxidative stress (hypochlorous acid ( $\mathrm{HOCl})$ and $\mathrm{NO}$ ) have been studied in murine cortical neuron cultures (Chen MJ and Cheung NS, unpublished data, submitted for publication). $\mathrm{HOCl}$ and $\mathrm{NO}$, natural biological components in mammals, are thermodynamically active molecules able to undergo vigorous chemical reactions with gaseous molecules, anions and ROS to form more stable and reactive products to escape their sequestration by the antioxidant systems, of which the latter decomposes further into multiple toxic products [125]. The resultant highly reactive electrophiles can in turn induce genotoxic damage, modulate protein activity through aberrant post-translational modifications, and alteration of mitochondrial energy metabolism. $\mathrm{HOCl}$ and NO are appropriately selected as each has been implicated in the pathogenesis of numerous inflammatory and oxidative stress - related neurological dysfunctions [10]. Furthermore, they are well-represented agents of neurodegenerative models through recapitulation of various pathological or morphological characteristics of the diseased state, and as mentioned above, microglia are a significant source of RONS external to neurons. Major biological pathways that are activated by the two stressors were monitored, to provide information on the detailed signal transduction processes and to enhance our understanding of the mechanisms invoked. In this work, as set out in Table $1, \mathrm{HOCl}$ was used directly whilst the NO donor NOC-18 was applied to the cultured cortical neurons. Some relevant data for changes in the gene expression profile in cortical neurons exposed to these two stressors are shown in Table 1.

Four main enzymes are responsible for the generation of oxidants within the phagocytes: reduced nicotinamide adenine dinucleotide phosphate (NADPH) oxidase, SOD, nitric oxide synthase (NOS) and myeloperoxidase (MPO). $\mathrm{O}_{2}^{-}$is formed as an undesirable product of the action of NADPH oxidase, a latent ETC located on the plasma membrane of the phagocytes [126]. As mentioned above, $\mathrm{O}_{2}^{-}$reacts rapidly with neighboring $\mathrm{O}_{2}^{-}$to form $\mathrm{H}_{2} \mathrm{O}_{2}$ spontaneously or catalytically accelerated by SOD via dismutation $[19,127]$. However, neither $\mathrm{O}_{2}^{-}$or $\mathrm{H}_{2} \mathrm{O}_{2}$ on its own possesses the high reactivity to adversely interact with biological molecules. Nonetheless, in the case of $\mathrm{H}_{2} \mathrm{O}_{2}$, the cellular damage induced can be further aggravated through the activity of MPO. This enzyme is a heme protein that catalyzes $\mathrm{H}_{2} \mathrm{O}_{2}$-mediated oxidation of halides to their respective hypohalous acids [128]. Pertaining to the high concentrations of halides in biological fluids, $\mathrm{Cl}^{-}$ is the predominant substrate for MPO forming $\mathrm{HOCl}$ as the major resultant oxidation product, i.e., close to $80 \%$ of the $\mathrm{H}_{2} \mathrm{O}_{2}$ produced by activated neutrophils is channeled to the formation of $20-400 \mu \mathrm{M} \mathrm{HOCl}$ per hour [128-130]. Within the brain, $\mathrm{HOCl}$ would then proceed to interact with $\mathrm{O}_{2}^{-}$and ferrous iron to form the dangerous $\mathrm{OH}$ radical. $\mathrm{HOCl}$ can also interact with nitrite $\left(\mathrm{NO}_{2}\right)$ radical (discussed below) to form nitryl chloride $\left(\mathrm{NO}_{2} \mathrm{Cl}\right)$, a cytotoxic product which possesses oxidizing, chlorinating and nitrating ability [131].

$\mathrm{NO}$ is a thermodynamically unstable free radical (NO) due to the presence of an unpaired electron in the outermost orbital. Within the mammalian brain, NO is produced predominantly by the NOS, a family comprising of four major types (namely neuronal NOS, endothelial NOS, mitochondrial NOS and inducible nitric oxide synthase (iNOS); these have been extensively reviewed in [132]. The former three NOS demonstrated constitutive activity and ubiquitous expression within the brain and especially neurons. For the latter, iNOS is expressed following immunological or inflammatory triggers in microglia, astrocytes and macrophages contributing to a massive accumulation of endogenous NO lasting hours or days [133]. Although NO is an important signaling molecule in its own right, due to its high thermodynamic instability NO can undergo vigorous interactions with other gaseous molecules (e.g., $\mathrm{O}_{2}$ ) resulting in the formation of nitrite $\left(\mathrm{NO}_{2}^{-}\right)$, nitrate with intermediate products such as $\mathrm{NO}_{2}$ and $\mathrm{OH}$ radicals that are highly reactive [134]. As mentioned above, a major NO interaction would be that with $\mathrm{O}_{2}^{-}$ 


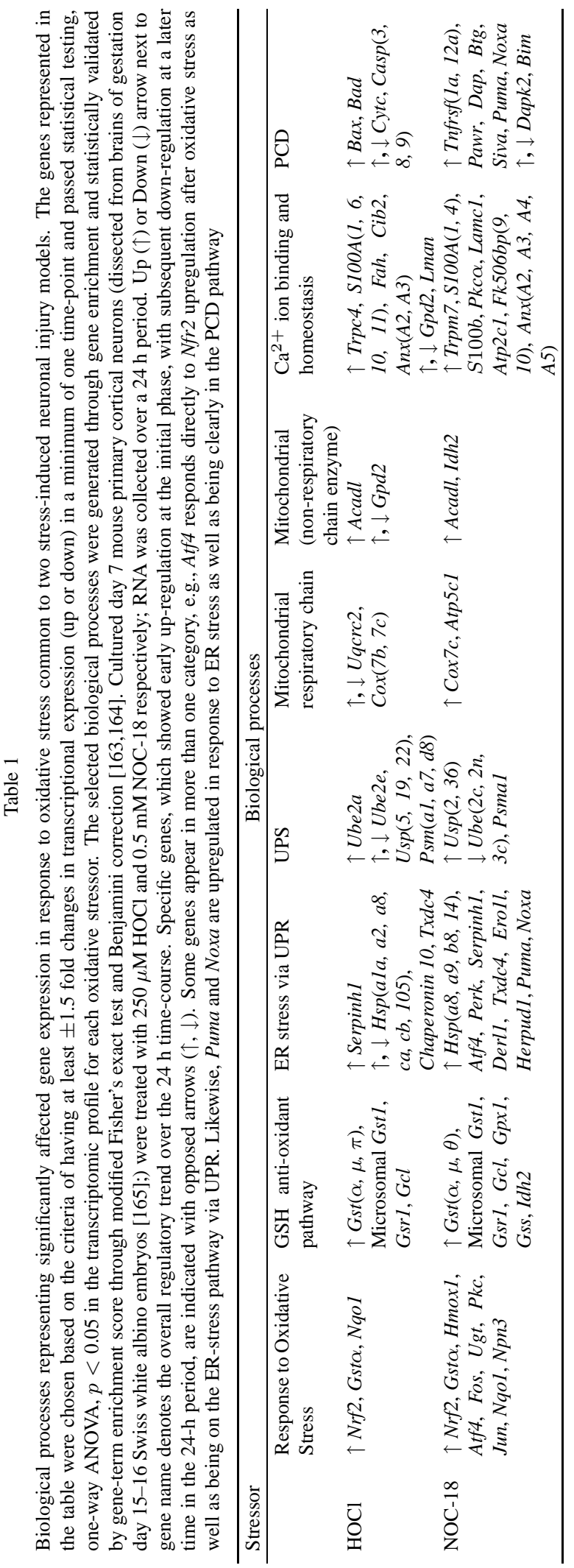


to form peroxynitrite anion $\left(\mathrm{ONOO}^{-}\right)$, thereby rendering inefficient its elimination via the antioxidant systems [125]. As such, the cellular toxicity created by the presence of $\mathrm{O}_{2}^{-}$is greatly enhanced by its downstream free radical derivatives, which can effectively chemically damage proteins (including mitochondrial enzymes leading to various types of mitochondrial and cellular debilitation $[19,135]$.

\section{Response to oxidative stress}

Various endogenous and exogenous sources contribute to the increase in oxidative load. Mitochondria, being the primary source of energy production, are a rich endogenous source of ROS through the ETC as discussed above. Other cellular processes leading to ROS formation include lipid peroxidation, metal ion-associated Fenton reactions, NO-mediated protein nitrosylation, and matrix enzymatic interactions [10, 136]. Cellular oxidative stress can trigger two opposing cellular responses: pro-survival and pro-death reactions. Pro-survival response to oxidative stress can be implemented at two different molecular stages, targeting transcriptional and post-translational modification systems, respectively.

Nuclear factor erythroid-related factor 2 (Nrf2), a pro-survival transcription factor ubiquitously expressed in the mammalian body [137], was recently demonstrated to possess neuroprotective function [138]. It is involved in the transcriptional activation of antioxidantresponse element (ARE)-containing genes encoding detoxifying enzymes and cytoprotective antioxidant proteins (e.g., SOD, NADPH dehydrogenase quinone1 (Nqol), and glutathione $S$-transferase (Gst)) [139]. In the event of cellular stress, rises in intracellular ROS and electrophiles induce the activation of several protein kinases, (e.g., protein kinase $\mathrm{C}(P k c)$ and PKRlike ER kinase (Perk)), which phosphorylate Nrf2, releasing it from cytoplasmic sequestration and facilitating its translocation into the nucleus where it binds to ARE sequence, leading to transcriptional activation of antioxidant enzymes (see review [140]).

Individual analytical results from the time-course global expression profiles of neurons treated with both stressors (first data column of Table 1) revealed Nrf2mediated transcriptional elevation of oxidative stressresponsive neuroprotective genes (e.g., $P k c$, activating transcription factor 4 (Atf4), Gst and heme oxygenase 1 (Hmox 1) along with Nrf2 elevated gene expression), reflecting the imposition of cellular stress. Especially in relation to NO treatment, numerous Nrf2 transcription- al downstream targets were significantly upregulated, which is a probable indication of an early evoked substantial response to oxidative stress. Proteins encoded by several Nrf2-induced transcriptional target genes also have prominent roles in ER stress response (see below), establishing the intimate regulatory feedback relationship between processes activated upon cellular oxidative and ER stresses. Other oxidative stress marker proteins are induced but these are not shown here.

\section{GSH antioxidant pathway}

The GSH pathway serves as a major effective cellular defense mechanism to reduce oxidative stress via sequestration of reactive nitrogen species and ROS. The induction of GSH-dependent detoxification enzymes such as Gst, Nqol and mitochondrial aldehyde dehydrogenase (Aldh) which use GSH, NAD(P)H and $\mathrm{NAD}(\mathrm{P})^{+}$as co-factors respectively, are important in detoxifying quinones and maintaining the cellular redox balance [141-143]. Indeed, from the microarray analyses, initiation and persistent activation of the GSH anti-oxidative pathway (second data column of Table 1) were evident from the significant transcriptional upregulation of its pathway members ( $G c l, G s t, G s r$ and Gpxl) and associated detoxifying enzymes (Nqol and Npn3). Altogether, the orchestrated transcriptional upregulation of detoxification enzymes and antioxidant proteins upon oxidative stress is a result of the presence of ARE in their promoters [144]. This has a synergistic effect in the maintenance of GSH levels as well as detoxification of reactive intermediates. It can be inferred that Nrf2-induced pathway plays a crucial role in propagating a strong anti-oxidative, pro-survival response against oxidative stress.

\section{ER stress}

ER stress, characterized by the accumulation of unfolded proteins in the ER lumen, is frequently associated with oxidative stress. Such ER stress induction can occur upon perturbation of any of ER cellular functions, including protein oxidation, disturbance of calcium signaling, and alteration of the homeostatic redox balance [145]. Upon ER stress, UPR is triggered to engender restoration of homeostatic balance [146]. During the initial phase of oxidative stress, when occurrence of cellular oxidative damage is still within ER tolerable threshold, UPR activates signaling pathways mediated by two ER-resident kinases, Perk and inositolrequiring enzyme (IRE1), and transcription factors Atf4 
and Atf6, which promote cell survival through the alleviation of ER burden. Mitigation of ER stress is achieved through increase in ER dynamic capacity to process unfolded and/or misfolded proteins by elevated expression of ER chaperones [146], and inhibition of cellular protein translation to decrease the buildup of newly synthesized, unassembled proteins by Perkmediated inhibitory phosphorylation of the eukaryotic initiation factor (eIF2 $\alpha$ ) [147].

However, once ER stress proceeds beyond the tolerable limit and homeostasis cannot be restored, UPR evokes a detrimental effect to send the cell to its demise. PCD pathways originating from ER stress responses can occur either dependent on or independently of the mitochondria. This occurs through the activation of caspase-12 and Atf6-induced CHOP activation, which ultimately leads to mitochondrial membrane permeabilization and subsequently to mitochondrial cell death pathways [148] or the activation of calpains by the ER calcium release, tending towards programmed necrosis [149].

Substantial ER stress is prominent from the gene expression profiles of the two oxidative stressor models (third data column in Table 1) with significant increase in gene expression of Atf4, Nrf2 and Perk, an indication of UPR activation. The increased gene expression of these UPR-related genes can occur as a consequence of Nrf2 transcriptional activation, as previously mentioned. Furthermore, ER-stress inducible chaperones (Txdc4, Hspal and Hspa2) and p53-mediated pro-apoptotic proteins (Puma and Noxa) also showed transcriptional up-regulation. We consider this to provide clear evidence for the occurrence of ER stress upon cellular oxidative exposure, resulting in trigger of UPR to counteract the accumulation of aberrant oxidized proteins and dysregulated intracellular ionic concentrations.

\section{Ubiquitin-proteasome system}

The UPS is a complex system which plays a primary role in eukaryotic protein clearance and quality control, where misfolded and/or excessively produced proteins are molecularly marked with poly-ubiquitins and dedicated for degradation by the proteasome [150]. Compromise in UPS efficiency has been reported in the aging process (see review [151]) and neurodegenerative disorders where aberrant protein inclusions have been observed [152]. UPS can be segregated into two distinct processes. First is the ubiquitinylation of the proteins destined for degradation, which is mediated by three enzymes namely, ubiquitin-activating enzyme E1 (Ube1), ubiquitin-conjugating enzyme E2 (Ube2) and ubiquitin protein ligase E3 (Ube3). Second is the subsequent targeting of the ubiquitin-linked protein/polypeptide to the proteasome for clearance.

Observations based on the temporal regulatory trend of UPS-related genes in the transcriptomic profile of the NO insults (fourth data column in Table 1) demonstrated some trends towards down-regulation of genes encoding ubiquitinylation enzymes (e.g., Ube2( $c$ and $n$ ) and $U b e 3 c$ ) and certain proteasome subunits (e.g., proteasome subunit alpha 1 (Psmal)). On the other hand, ubiquitin-specific peptidases (e.g., Usp2 andUsp36), which function as deubiquitinylating enzymes, demonstrated significant up-regulation, providing further evidence of the decreased efficiency of UPS function. Intriguingly, an early initial up-regulation of UPS genes that eventually falters with time is especially prominent in HOCl-mediated neuronal injury, and not apparent for the other stressors. This suggests a regulatory cellular feedback mechanism may be at play, in an attempt to reverse the detrimental effects of proteasomal inhibition, which can result in cell death [153]. This difference is evident when observing the transcriptional regulatory trend of Psmal across both stressor models. The Psma family is a group of peptidases forming the alpha subunits of the 20S core structure of the multicatalytic proteinase complex. Following $\mathrm{HOCl}$ treatment there was an early elevation and subsequent decline in Psmal gene expression. However, for NO treatment, neurons demonstrated an ongoing transcriptional down-regulation of Psmal.

\section{Mitochondrial respiratory chain}

Perturbation of mitochondrial function has been suggested to play a major role in the pathogenesis of neurological disorders where evidence of oxidative stress has been observed, as discussed above. Transcriptomic analysis revealed substantial differential regulation of gene expression relating to many mitochondrial proteins, some in the oxidative phosphorylation and ETC processes. Some examples are shown in Table 1 (fifth and sixth data columns). Main components of the mitochondrial ETC, namely complexes I to IV, demonstrated primarily significant down-regulation scattered across the stressor models (data not shown). Mitochondrial complex IV demonstrated significant transcriptional regulation across both oxidative stressor models. On the contrary, other non-mitochondrial microsomal electron transferring pathways such as the cy- 
tochrome p450 family (Cyp), and cytochrome b5 reductase $(C y b 5)$ demonstrated up-regulation (data not shown in Table 1), which represents a probable compensatory attempt to make up for the cellular energy deficit. Similarly, other proteins also involved in energy metabolism (e.g., glycerol-3-phosphate dehydrogenase $(G p d)$, acyl-coenzyme A dehydrogenase (Acad) and isocitrate dehydrogenase $(I d h)$ ) also showed elevated gene expression.

\section{Calcium binding and homeostasis}

Management of calcium homeostasis is critical to cellular wellbeing due to the presence of a variety of calcium-activated protein families that can evoke two antagonistic outcomes: cell survival or death. Such outcomes are mediated by calcium released from specific calcium compartments through different calcium channel subtypes, which stimulate calcium-dependent proteins at specific subcellular localizations. Cells have an intrinsic fail-safe system, implemented by the mitochondria, to combat sudden and temporary surge in intracellular calcium levels as a result of oxidative stress (reviewed in [136]). Mitochondria regulate cellular calcium signals by acting as a temporary calcium buffer and respond to calcium elevations by increasing the cell energy supply [154]. However, upon abnormal calcium homeostasis arising from prolonged ER stress and increased ROS production, a series of intracellular signaling cascades are activated which can lead to apoptosis through the activation of calcium-activated calpains [155]. Detailed analysis of the transcriptomic profiling of both stressor models (seventh data column of Table 1) demonstrated significant up-regulated gene expression of proteins involved in calcium binding and homeostasis which comprised of calcium-activated proteins such as S100A and Fk506 calcium binding protein families and annexins (Anx family). The calciummodulated S100 binding protein family (S100), significantly up-regulated in both stressor models, is the largest EF-hand protein subfamily involved in regulation of protein phosphorylation, cell growth and motility, cell-cycle regulation, transcription, differentiation and cell survival [156]. It is apparent that the diversity in functions of numerous calcium-dependent proteins contributes to cell homeostasis, and their fate is dependent on the net outcome of the downstream prosurvival and pro-death calcium-stimulated protein signaling cascades. Presence of excess cytosolic calcium ions due to aberrant calcium homeostasis resulted in activation of calcium-dependent signaling mechanisms implicated in various cellular function regulation. As such, we postulate calcium-dependent proteins demonstrated elevated gene expression to meet the continued stimulation by the excess intracellular calcium ions and the need for sustenance of propagation of these pathways.

\section{Cell death}

It is evident from the microarray analysis that cell death mechanisms, either dependent on or independent of mitochondria, are involved in neuronal death in each distinct treatment (last data column in Table 1). Prominent genes affected by $\mathrm{HOCl}$ treatment include mitochondria-activating $\mathrm{BH} 3$-only proteins Bax and $\mathrm{Bad}$, and also cyt $\mathrm{c}$ and caspase- 3 . These findings indicate that the intrinsic apoptotic pathway leads to PCD following $\mathrm{HOCl}$ treatment. However, these changes were not so evident following the NO treatment, which included changes in TNF receptors tnfrsf1, death associated protein (Dap) and Pawr (another pro-apoptotic protein). This outcome indicates that possibly other PCD pathways are invoked in these neurons following treatment with NO. Failure of the neurons to significantly upregulate caspases following NO treatment suggests that possibly these are dependent on other non-apoptotic pathways to invoke cell death.

Programmed necrosis involving the activation of the calcium-dependent proteases, calpains, has been reported in neuronal death induced by $\mathrm{HOCl}$ and NO [42,157-159]. Transcriptional evidence consistent with programmed necrosis has been mentioned above, considering the significant up-regulated expression of the genes involved in calcium binding and homeostasis (seventh column of Table 1), including calciumactivated proteins such as S100bps, AnxAs and Pkca. In addition, previous reports demonstrated calpains to be implicated in the cleavage-mediated activation of endogenous caspases such as caspase $-3,-7,-8$ and -9 in both oxidative stressor models [160], although such changes would not necessarily be detected at the transcriptional level.

Elaboration of the type of data obtained by transcriptional analysis, as shown above, will shed further light on specific details of the apoptosis-necrosis continuum of neuronal death, which takes place consequential to induction of oxidative stress. With regulatory feedback loops and cross-talk between different modes of PCD, it is presently impossible to clearly dissect one mode from the other, as they run in parallel. One broad goal of these approaches is to identify potential biological 
targets within the PCD cascades, as there is the possibility of inhibiting multiple pro-death pathways through single target suppression. As such, it is important that PCD be viewed as a single complex, multi-pathway process.

\section{CONCLUSIONS}

In this review we have provided an overview of the role of oxidative stress in neuronal injury and neurodegenerative disease, with a focus on the cellular aspects. Mitochondria and other organelles, including ER, play a central role in the pathways leading to cell death. The modes of cell death are varied and are influenced by many factors, including the cell type, the stressor and the setting. In context of diseases such as AD, PD and others that are recognized as protein aggregation disorders, the formation of such aggregates provides an additional factor exacerbating the cellular stresses leading to neurodegeneration and cell death. While studies at the cellular level have limitations in terms of understanding the detailed pathophysiological process leading to disease in the intact organism (humans or animal models of particular diseases), they do provide the key underpinnings of molecular and cellular pathways, on the basis of which the behaviors of cells, tissues and organs in the more complex milieu of the mammal can be deciphered. Based upon the involvement of multiple upstream mechanisms and cellular compartments in PCD one can present a case for "polypharmacy" strategies, although recent advances with targeted approaches such as those directed at mitochondrially generated RONS show considerable promise for cytoprotection $[161,162]$. In this light, future advances in our understanding of how mechanisms up-stream and downstream of mitochondria contribute to PCD in AD and other neurodegenerative disorders will see an explosion of information on this topic. Along with the more detailed appreciation of intracellular networks of signaling involving different organelles (as considered here), and in other work that leads to increased, understanding of communication between different cell types in the central nervous system, we can expect improved clarity on the etiology of AD, PD and related pathologies, as well as better and more effective therapeutics.

\section{DISCLOSURE STATEMENTS}

Authors' disclosures available online (http://www.jalz.com/disclosures/view.php?id=423).

\section{REFERENCES}

[1] Jenner P (2007) Oxidative stress and Parkinson's disease. Handb Clin Neurol 83, 507-520.

[2] Pratico D (2008) Evidence of oxidative stress in Alzheimer's disease brain and antioxidant therapy. Ann N Y Acad Sci 1147, 70-78.

[3] Crack PJ, Taylor JM (2005) Reactive oxygen species and the modulation of stroke. Free Radic Biol Med 38, 1433-1444.

[4] Cooper AJL (1997) Glutathione in the brain: disorders of glutathione metabolism In The Molecular and Genetic Basis of Neurological Disease, Rosenberg RN, Prusiner SB, Di Mauro S, Barchi RL, Kunk LM, eds., Butterworth-Heinemann, Boston, pp. 1195-1230.

[5] Koutsilieri E, Scheller C, Tribl F, Riederer P (2002) Degeneration of neuronal cells due to oxidative stress - microglial contribution. Parkinsonism Relat Disord 8, 401-406.

[6] Andersen JK (2004) Oxidative stress in neurodegeneration: cause or consequence? Nat Med 10 Suppl, S18-25.

[7] Lenaz G, Bovina C, D'Aurelio M, Fato R, Formiggini G, Genova ML, Giuliano G, Merlo Pich M, Paolucci U, Parenti Castelli G, Ventura B (2002) Role of mitochondria in oxidative stress and aging. Ann N Y Acad Sci 959, 199-213.

[8] McLennan HR, Degli Esposti M (2000) The contribution of mitochondrial respiratory complexes to the production of reactive oxygen species. J Bioenerg Biomembr 32, 153-162.

[9] Sayre LM, Perry G, Smith MA (2008) Oxidative stress and neurotoxicity. Chem Res Toxicol 21, 172-188.

[10] Halliwell B (2006) Oxidative stress and neurodegeneration: where are we now? J Neurochem 97, 1634-1658.

[11] Shivakumar BR, Anandatheerthavarada HK, Ravindranath V (1991) Free radical scavenging systems in developing rat brain. Int J Dev Neurosci 9, 181-185.

[12] Hussain S, Slikker W, Jr., Ali SF (1995) Age-related changes in antioxidant enzymes, superoxide dismutase, catalase, glutathione peroxidase and glutathione in different regions of mouse brain. Int J Dev Neurosci 13, 811-817.

[13] Sohal RS, Sohal BH, Brunk UT (1990) Relationship between antioxidant defenses and longevity in different mammalian species. Mech Ageing Dev 53, 217-227.

[14] Dringen R, Kussmaul L, Gutterer JM, Hirrlinger J, Hamprecht B (1999) The glutathione system of peroxide detoxification is less efficient in neurons than in astroglial cells. $J$ Neurochem 72, 2523-2530.

[15] Siu AW, Reiter RJ, To CH (1998) The efficacy of vitamin E and melatonin as antioxidants against lipid peroxidation in rat retinal homogenates. J Pineal Res 24, 239-244.

[16] Dringen R, Hirrlinger J (2003) Glutathione pathways in the brain. Biol Chem 384, 505-516.

[17] Dringen R, Pfeiffer B, Hamprecht B (1999) Synthesis of the antioxidant glutathione in neurons: supply by astrocytes of CysGly as precursor for neuronal glutathione. J Neurosci $\mathbf{1 9}$, 562-569.

[18] Finkel T, Holbrook NJ (2000) Oxidants, oxidative stress and the biology of ageing. Nature 408, 239-247.

[19] Yap Y, Whiteman M, Cheung N (2007) Chlorinative stress: An under appreciated mediator of neurodegeneration? Cell Signal 19, 219-228.

[20] Benveniste E (1997) Role of macrophages/microglia in multiple sclerosis and experimental allergic encephalomyelitis. J Mol Med 75, 165-173.

[21] Tahara EB, Navarete FD, Kowaltowski AJ (2009) Tissue-, substrate-, and site-specific characteristics of mitochondrial 
reactive oxygen species generation. Free Radic Biol Med 46 , 1283-1297.

[22] Gu Z, Nakamura T, Lipton SA (2010) Redox reactions induced by nitrosative stress mediate protein misfolding and mitochondrial dysfunction in neurodegenerative diseases. Mol Neurobiol, in press.

[23] Murphy MP (2009) How mitochondria produce reactive oxygen species. Biochem J 417, 1-13.

[24] Devi L, Anandatheerthavarada HK (2010) Mitochondrial trafficking of APP and alpha synuclein: Relevance to mitochondrial dysfunction in Alzheimer's and Parkinson's diseases. Biochim Biophys Acta 1802, 11-19.

[25] Balaban RS, Nemoto S, Finkel T (2005) Mitochondria, oxidants, and aging. Cell 120, 483-495.

[26] Droge W, Schipper HM (2007) Oxidative stress and aberrant signaling in aging and cognitive decline. Aging Cell 6, 361370.

[27] Crack PJ, Cimdins K, Ali U, Hertzog PJ, Iannello RC (2006) Lack of glutathione peroxidase-1 exacerbates Abetamediated neurotoxicity in cortical neurons. J Neural Transm 113, 645-657.

[28] de Haan JB, Bladier C, Griffiths P, Kelner M, O'Shea RD, Cheung NS, Bronson RT, Silvestro MJ, Wild S, Zheng SS, Beart PM, Hertzog PJ, Kola I (1998) Mice with a homozygous null mutation for the most abundant glutathione peroxidase, Gpx1, show increased susceptibility to the oxidative stress-inducing agents paraquat and hydrogen peroxide. J Biol Chem 273, 22528-22536.

[29] Shults CW, Oakes D, Kieburtz K, Beal MF, Haas R, Plumb S, Juncos JL, Nutt J, Shoulson I, Carter J, Kompoliti K, Perlmutter JS, Reich S, Stern M, Watts RL, Kurlan R, Molho E, Harrison M, Lew M (2002) Effects of coenzyme Q10 in early Parkinson disease: evidence of slowing of the functional decline. Arch Neurol 59, 1541-1550.

[30] Nagley P, Higgins GC, Atkin JD, Beart PM (2010) Multifaceted deaths orchestrated by mitochondria in neurones. Biochim Biophys Acta 1802, 167-185.

[31] Hyun DH, Gray DA, Halliwell B, Jenner P (2004) Interference with ubiquitination causes oxidative damage and increased protein nitration: implications for neurodegenerative diseases. J Neurochem 90, 422-430.

[32] Kroemer G, Galluzzi L, Brenner C (2007) Mitochondrial membrane permeabilization in cell death. Physiol Rev 87, 99-163.

[33] Smith DJ, Ng H, Kluck RM, Nagley P (2008) The mitochondrial gateway to cell death. IUBMB Life 60, 383-389.

[34] Starkov AA, Chinopoulos C, Fiskum G (2004) Mitochondrial calcium and oxidative stress as mediators of ischemic brain injury. Cell Calcium 36, 257-264.

[35] Toescu EC, Verkhratsky A (2003) Neuronal ageing from an intraneuronal perspective: roles of endoplasmic reticulum and mitochondria. Cell Calcium 34, 311-323.

[36] Camello-Almaraz C, Gomez-Pinilla PJ, Pozo MJ, Camello PJ (2006) Mitochondrial reactive oxygen species and $\mathrm{Ca} 2+$ signaling. Am J Physiol Cell Physiol 291, C1082-C1088.

[37] Starkov AA, Polster BM, Fiskum G (2002) Regulation of hydrogen peroxide production by brain mitochondria by calcium and Bax. J Neurochem 83, 220-228.

[38] Rizzuto R, Pozzan T (2006) Microdomains of intracellular $\mathrm{Ca} 2+$ : molecular determinants and functional consequences. Physiol Rev 86, 369-408.

[39] Nixon RA (2007) Autophagy, amyloidogenesis and Alzheimer disease. J Cell Sci 120, 4081-4091.
[40] Reddy PH (2009) Amyloid beta, mitochondrial structural and functional dynamics in Alzheimer's disease. Exp Neurol 218, 286-292.

[41] Takahashi K, Niidome T, Akaike A, Kihara T, Sugimoto H (2009) Amyloid precursor protein promotes endoplasmic reticulum stress-induced cell death via C/EBP homologous protein-mediated pathway. J Neurochem 109, 1324-1337.

[42] Cheung NS, Pascoe CJ, Giardina SF, John CA, Beart PM (1998) Micromolar L-glutamate induces extensive apoptosis in an apoptotic-necrotic continuum of insult-dependent, excitotoxic injury in cultured cortical neurones. Neuropharmacology 37, 1419-1429.

[43] Blomgren K, Leist M, Groc L (2007) Pathological apoptosis in the developing brain. Apoptosis 12, 993-1010.

[44] Degterev A, Yuan J (2008) Expansion and evolution of cell death programmes. Nat Rev Mol Cell Biol 9, 378-390.

[45] Gill MB, Perez-Polo JR (2008) Hypoxia ischemia-mediated cell death in neonatal rat brain. Neurochem Res 33, 23792389.

[46] Diwakarla S, Nagley P, Hughes ML, Chen B, Beart PM (2009) Differential insult-dependent recruitment of the intrinsic mitochondrial pathway during neuronal programmed cell death. Cell Mol Life Sci 66, 156-172.

[47] Shin YS, Chu PW, Mercer LD, Higgins GC, O'Shea RD, Nagley P, Beart PM (2009) Mitochondrial injury and programmed cell death inducing apoptosis, autophagy and endoplasmic reticulum stress in neuronal injury. $J$ Neurochem 110, 41.

[48] Liu Y, Schubert DR (2009) The specificity of neuroprotection by antioxidants. J Biomed Sci 16, 98.

[49] Gibson GE, Starkov A, Blass JP, Ratan RR, Beal MF (2010) Cause and consequence: Mitochondrial dysfunction initiates and propagates neuronal dysfunction, neuronal death and behavioral abnormalities in age-associated neurodegenerative diseases. Biochim Biophys Acta 1802, 122-134.

[50] Moreira PI, Carvalho C, Zhu X, Smith MA, Perry G (2010) Mitochondrial dysfunction is a trigger of Alzheimer's disease pathophysiology. Biochim Biophys Acta 1802, 2-10.

[51] Smith MA, Zhu X, Tabaton M, Liu G, McKeel DW, Jr., Cohen ML, Wang X, Siedlak SL, Dwyer BE, Hayashi T, Nakamura M, Nunomura A, Perry G (2010) Increased iron and free radical generation in preclinical Alzheimer disease and mild cognitive impairment. J Alzheimers Dis 19, 363-372.

[52] de la Monte SM, Sohn YK, Wands JR (1997) Correlates of p53- and Fas (CD95)-mediated apoptosis in Alzheimer's disease. J Neurol Sci 152, 73-83.

[53] Jesionek-Kupnicka D, Buczynski J, Kordek R, Sobow T, Kloszewska I, Papierz W, Liberski PP (1997) Programmed cell death (apoptosis) in Alzheimer's disease and CreutzfeldtJakob disease. Folia Neuropathol 35, 233-235.

[54] Stadelmann C, Bruck W, Bancher C, Jellinger K, Lassmann H (1998) Alzheimer disease: DNA fragmentation indicates increased neuronal vulnerability, but not apoptosis. $J \mathrm{Neu}$ ropathol Exp Neurol 57, 456-464.

[55] Su JH, Deng G, Cotman CW (1997) Bax protein expression is increased in Alzheimer's brain: correlations with DNA damage, Bcl-2 expression, and brain pathology. J Neuropathol Exp Neurol 56, 86-93.

[56] Cataldo AM, Hamilton DJ, Barnett JL, Paskevich PA, Nixon RA (1996) Properties of the endosomal-lysosomal system in the human central nervous system: disturbances mark most neurons in populations at risk to degenerate in Alzheimer's disease. J Neurosci 16, 186-199. 
[57] Cheung YT, Zhang NQ, Hung CH, Lai CS, Yu MS, So KF, Chang RC (2009) Temporal relationship of autophagy and apoptosis in neurons challenged by low molecular weight beta-amyloid peptide. J Cell Mol Med, in press.

[58] Hung SY, Huang WP, Liou HC, Fu WM (2009) Autophagy protects neuron from Abeta-induced cytotoxicity. Autophagy 5, 502-510.

[59] Pickford F, Masliah E, Britschgi M, Lucin K, Narasimhan R, Jaeger PA, Small S, Spencer B, Rockenstein E, Levine B, Wyss-Coray T (2008) The autophagy-related protein beclin 1 shows reduced expression in early Alzheimer disease and regulates amyloid beta accumulation in mice. J Clin Invest 118, 2190-2199.

[60] Yang DS, Kumar A, Stavrides P, Peterson J, Peterhoff CM, Pawlik M, Levy E, Cataldo AM, Nixon RA (2008) Neuronal apoptosis and autophagy cross talk in aging PS/APP mice, a model of Alzheimer's disease. Am J Pathol 173, 665-681.

[61] Banerjee R, Starkov AA, Beal MF, Thomas B (2009) Mitochondrial dysfunction in the limelight of Parkinson's disease pathogenesis. Biochim Biophys Acta 1792, 651-663.

[62] Iuso A, Scacco S, Piccoli C, Bellomo F, Petruzzella V, Trentadue R, Minuto M, Ripoli M, Capitanio N, Zeviani M, Papa S (2006) Dysfunctions of cellular oxidative metabolism in patients with mutations in the NDUFS1 and NDUFS4 genes of complex I. J Biol Chem 281, 10374-10380.

[63] Chu CT, Zhu JH, Cao G, Signore A, Wang S, Chen J (2005) Apoptosis inducing factor mediates caspase-independent 1methyl-4-phenylpyridinium toxicity in dopaminergic cells. $J$ Neurochem 94, 1685-1695.

[64] Lim ML, Mercer LD, Nagley P, Beart PM (2007) Rotenone and $\mathrm{MPP}+$ preferentially redistribute apoptosis-inducing factor in apoptotic dopamine neurons. Neuroreport 18, 307312.

[65] Chinta SJ, Rane A, Yadava N, Andersen JK, Nicholls DG, Polster BM (2009) Reactive oxygen species regulation by AIF- and complex I-depleted brain mitochondria. Free Radic Biol Med 46, 939-947.

[66] Benit P, Goncalves S, Dassa EP, Briere JJ, Rustin P (2008) The variability of the harlequin mouse phenotype resembles that of human mitochondrial-complex I-deficiency syndromes. PLoS One 3, e3208.

[67] Tinsley RB, Bye CR, Parish CL, Tziotis-Vais A, George S, Culvenor JG, Li QX, Masters CL, Finkelstein DI, Horne MK (2009) Dopamine D2 receptor knockout mice develop features of Parkinson disease. Ann Neurol 66, 472-484.

[68] Levy OA, Malagelada C, Greene LA (2009) Cell death pathways in Parkinson's disease: proximal triggers, distal effectors, and final steps. Apoptosis 14, 478-500.

[69] Cocheme HM, Murphy MP (2009) Chapter 22 The uptake and interactions of the redox cycler paraquat with mitochondria. Methods Enzymol 456, 395-417.

[70] Drechsel DA, Patel M (2009) Differential contribution of the mitochondrial respiratory chain complexes to reactive oxygen species production by redox cycling agents implicated in parkinsonism. Toxicol Sci 112, 427-434.

[71] Choi WS, Kruse SE, Palmiter RD, Xia Z (2008) Mitochondrial complex I inhibition is not required for dopaminergic neuron death induced by rotenone, MPP + , or paraquat. Proc Natl Acad Sci U S A 105, 15136-15141.

[72] Browne SE (2008) Mitochondria and Huntington's disease pathogenesis: insight from genetic and chemical models. Ann N Y Acad Sci 1147, 358-382.
[73] Damiano M, Galvan L, Deglon N, Brouillet E (2010) Mitochondria in Huntington's disease. Biochim Biophys Acta 1802, 52-61.

[74] Brouillet E, Jacquard C, Bizat N, Blum D (2005) 3Nitropropionic acid: a mitochondrial toxin to uncover physiopathological mechanisms underlying striatal degeneration in Huntington's disease. J Neurochem 95, 1521-1540.

[75] Diwakarla S, Mercer LD, Kardashsyan L, Chu PW, Shin YS, Lau CL, Hughes ML, Nagley P, Beart PM (2009) GABAergic striatal neurons exhibit caspase-independent, mitochondrially mediated programmed cell death. J Neurochem 109 Suppl 1, 198-206.

[76] Benchoua A, Trioulier Y, Zala D, Gaillard MC, Lefort N, Dufour N, Saudou F, Elalouf JM, Hirsch E, Hantraye P, Deglon $\mathrm{N}$, Brouillet $\mathrm{E}$ (2006) Involvement of mitochondrial complex II defects in neuronal death produced by N-terminus fragment of mutated huntingtin. Mol Biol Cell 17, 1652-1663.

[77] Reddy PH, Mao P, Manczak M (2009) Mitochondrial structural and functional dynamics in Huntington's disease. Brain Res Rev 61, 33-48.

[78] Sarkar S, Ravikumar B, Floto RA, Rubinsztein DC (2009) Rapamycin and mTOR-independent autophagy inducers ameliorate toxicity of polyglutamine-expanded huntingtin and related proteinopathies. Cell Death Differ 16, 46-56.

[79] Borthwick GM, Johnson MA, Ince PG, Shaw PJ, Turnbull DM (1999) Mitochondrial enzyme activity in amyotrophic lateral sclerosis: implications for the role of mitochondria in neuronal cell death. Ann Neurol 46, 787-790.

[80] Mahad DJ, Ziabreva I, Campbell G, Lax N, White K, Hanson PS, Lassmann H, Turnbull DM (2009) Mitochondrial changes within axons in multiple sclerosis. Brain 132, 11611174

[81] Niizuma K, Endo H, Nito C, Myer DJ, Chan PH (2009) Potential role of PUMA in delayed death of hippocampal CA1 neurons after transient global cerebral ischemia. Stroke 40, 618-625.

[82] Steckley D, Karajgikar M, Dale LB, Fuerth B, Swan P, Drummond-Main C, Poulter MO, Ferguson SS, Strasser A, Cregan SP (2007) Puma is a dominant regulator of oxidative stress induced Bax activation and neuronal apoptosis. $J$ Neurosci 27, 12989-12999.

[83] Willis SN, Chen L, Dewson G, Wei A, Naik E, Fletcher JI, Adams JM, Huang DC (2005) Proapoptotic Bak is sequestered by $\mathrm{Mcl}-1$ and $\mathrm{Bcl}-\mathrm{xL}$, but not $\mathrm{Bcl}-2$, until displaced by BH3-only proteins. Genes Dev 19, 1294-1305.

[84] Wyttenbach A, Tolkovsky AM (2006) The BH3-only protein Puma is both necessary and sufficient for neuronal apoptosis induced by DNA damage in sympathetic neurons. J Neurochem 96, 1213-1226.

[85] Fei Q, McCormack AL, Di Monte DA, Ethell DW (2008) Paraquat neurotoxicity is mediated by a Bak-dependent mechanism. J Biol Chem 283, 3357-3364.

[86] Beart PM, Lim ML, Chen B, Diwakarla S, Mercer LD, Cheung NS, Nagley P (2007) Hierarchical recruitment by AMPA but not staurosporine of pro-apoptotic mitochondrial signaling in cultured cortical neurons: evidence for caspasedependent/independent cross-talk. J Neurochem 103, 24082427.

[87] Higgins GC, Beart PM, Nagley P (2009) Oxidative stress triggers neuronal caspase-independent death: endonuclease $\mathrm{G}$ involvement in programmed cell death-type III. Cell Mol Life Sci 66, 2773-2787. 
[88] Valencia A, Moran J (2004) Reactive oxygen species induce different cell death mechanisms in cultured neurons. Free Radic Biol Med 36, 1112-1125.

[89] Todde V, Veenhuis M, van der Klei IJ (2009) Autophagy: principles and significance in health and disease. Biochim Biophys Acta 1792, 3-13.

[90] Terman A, Gustafsson B, Brunk UT (2006) Mitochondrial damage and intralysosomal degradation in cellular aging. Mol Aspects Med 27, 471-482.

[91] Tolkovsky AM (2009) Mitophagy. Biochim Biophys Acta 1793, 1508-1515.

[92] Chen H, Chan DC (2009) Mitochondrial dynamics - fusion, fission, movement, and mitophagy - in neurodegenerative diseases. Hum Mol Genet 18, R169-176.

[93] Perkins G, Bossy-Wetzel E, Ellisman MH (2009) New insights into mitochondrial structure during cell death. Exp Neurol 218, 183-192.

[94] Barsoum MJ, Yuan H, Gerencser AA, Liot G, Kushnareva Y, Graber S, Kovacs I, Lee WD, Waggoner J, Cui J, White AD, Bossy B, Martinou JC, Youle RJ, Lipton SA, Ellisman MH, Perkins GA, Bossy-Wetzel E (2006) Nitric oxide-induced mitochondrial fission is regulated by dynamin-related GTPases in neurons. EMBO J 25, 3900-3911.

[95] Kroemer G, Levine B (2008) Autophagic cell death: the story of a misnomer. Nat Rev Mol Cell Biol 9, 1004-1010.

[96] Zhu X, Raina AK, Perry G, Smith MA (2006) Apoptosis in Alzheimer disease: a mathematical improbability. Curr Alzheimer Res 3, 393-396.

[97] Raina AK, Hochman A, Zhu X, Rottkamp CA, Nunomura A, Siedlak SL, Boux H, Castellani RJ, Perry G, Smith MA (2001) Abortive apoptosis in Alzheimer's disease. Acta Neuropathol 101, 305-310.

[98] Moreira PI, Siedlak SL, Wang X, Santos MS, Oliveira CR, Tabaton M, Nunomura A, Szweda LI, Aliev G, Smith MA, Zhu X, Perry G (2007) Autophagocytosis of mitochondria is prominent in Alzheimer disease. J Neuropathol Exp Neurol 66, 525-532.

[99] Zheng L, Roberg K, Jerhammar F, Marcusson J, Terman A (2006) Oxidative stress induces intralysosomal accumulation of Alzheimer amyloid beta-protein in cultured neuroblastoma cells. Ann N Y Acad Sci 1067, 248-251.

[100] Zheng L, Kagedal K, Dehvari N, Benedikz E, Cowburn R, Marcusson J, Terman A (2009) Oxidative stress induces macroautophagy of amyloid beta-protein and ensuing apoptosis. Free Radic Biol Med 46, 422-429.

[101] Vila M, Ramonet D, Perier C (2008) Mitochondrial alterations in Parkinson's disease: new clues. J Neurochem 107, 317-328.

[102] Darios F, Corti O, Lucking CB, Hampe C, Muriel MP, Abbas N, Gu WJ, Hirsch EC, Rooney T, Ruberg M, Brice A (2003) Parkin prevents mitochondrial swelling and cytochrome $\mathrm{c}$ release in mitochondria-dependent cell death. Hum Mol Genet 12, 517-526.

[103] Dagda RK, Cherra SJ, 3rd, Kulich SM, Tandon A, Park D, Chu CT (2009) Loss of PINK1 function promotes mitophagy through effects on oxidative stress and mitochondrial fission. J Biol Chem 284, 13843-13855.

[104] Palacino JJ, Sagi D, Goldberg MS, Krauss S, Motz C, Wacker M, Klose J, Shen J (2004) Mitochondrial dysfunction and oxidative damage in parkin-deficient mice. J Biol Chem $\mathbf{2 7 9}$, 18614-18622.

[105] Exner N, Treske B, Paquet D, Holmstrom K, Schiesling C, Gispert S, Carballo-Carbajal I, Berg D, Hoepken HH, Gasser T, Kruger R, Winklhofer KF, Vogel F, Reichert AS, Auburger
G, Kahle PJ, Schmid B, Haass C (2007) Loss-of-function of human PINK1 results in mitochondrial pathology and can be rescued by parkin. J Neurosci 27, 12413-12418.

[106] Petit A, Kawarai T, Paitel E, Sanjo N, Maj M, Scheid M, Chen F, Gu Y, Hasegawa H, Salehi-Rad S, Wang L, Rogaeva E, Fraser P, Robinson B, St George-Hyslop P, Tandon A (2005) Wild-type PINK1 prevents basal and induced neuronal apoptosis, a protective effect abrogated by Parkinson disease-related mutations. J Biol Chem 280, 34025-34032.

[107] Pridgeon JW, Olzmann JA, Chin LS, Li L (2007) PINK1 protects against oxidative stress by phosphorylating mitochondrial chaperone TRAP1. PLoS Biol 5, e172.

[108] Strauss KM, Martins LM, Plun-Favreau H, Marx FP, Kautzmann S, Berg D, Gasser T, Wszolek Z, Muller T, Bornemann A, Wolburg H, Downward J, Riess O, Schulz JB, Kruger $\mathrm{R}$ (2005) Loss of function mutations in the gene encoding Omi/HtrA2 in Parkinson's disease. Hum Mol Genet 14, 20992111

[109] Plun-Favreau H, Klupsch K, Moisoi N, Gandhi S, Kjaer S, Frith D, Harvey K, Deas E, Harvey RJ, McDonald N, Wood NW, Martins LM, Downward J (2007) The mitochondrial protease HtrA2 is regulated by Parkinson's diseaseassociated kinase PINK1. Nat Cell Biol 9, 1243-1252.

[110] Yun J, Cao JH, Dodson MW, Clark IE, Kapahi P, Chowdhury RB, Guo M (2008) Loss-of-function analysis suggests that Omi/HtrA2 is not an essential component of the PINK1/PARKIN pathway in vivo. J Neurosci 28, 1450014510.

[111] Narendra D, Tanaka A, Suen DF, Youle RJ (2009) Parkininduced mitophagy in the pathogenesis of Parkinson disease. Autophagy 5, 706-708.

[112] Vives-Bauza C, Zhou C, Huang Y, Cui M, de Vries RL, Kim J, May J, Tocilescu MA, Liu W, Ko HS, Magrane J, Moore DJ, Dawson VL, Grailhe R, Dawson TM, Li C, Tieu K, Przedborski S PINK1-dependent recruitment of Parkin to mitochondria in mitophagy. Proc Natl Acad Sci U S A 107, 378-383.

[113] Whitworth AJ, Pallanck LJ (2009) The PINK1/Parkin pathway: a mitochondrial quality control system? J Bioenerg Biomembr 41, 499-503.

[114] Taira T, Saito Y, Niki T, Iguchi-Ariga SM, Takahashi K, Ariga $\mathrm{H}$ (2004) DJ-1 has a role in antioxidative stress to prevent cell death. ЕMBO Rep 5, 213-218.

[115] Lavara-Culebras E, Paricio N (2007) Drosophila DJ-1 mutants are sensitive to oxidative stress and show reduced lifespan and motor deficits. Gene 400, 158-165.

[116] Zhou W, Freed CR (2005) DJ-1 up-regulates glutathione synthesis during oxidative stress and inhibits A53T alphasynuclein toxicity. J Biol Chem 280, 43150-43158.

[117] Yokota T, Sugawara K, Ito K, Takahashi R, Ariga H, Mizusawa $H$ (2003) Down regulation of DJ-1 enhances cell death by oxidative stress, ER stress, and proteasome inhibition. Biochem Biophys Res Commun 312, 1342-1348.

[118] Baulac S, Lu H, Strahle J, Yang T, Goldberg MS, Shen J, Schlossmacher MG, Lemere CA, Lu Q, Xia W (2009) Increased DJ-1 expression under oxidative stress and in Alzheimer's disease brains. Mol Neurodegener 4, 12.

[119] Nakka VP, Gusain A, Mehta SL, Raghubir R (2008) Molecular mechanisms of apoptosis in cerebral ischemia: multiple neuroprotective opportunities. Mol Neurobiol 37, 7-38.

[120] Scherz-Shouval R, Elazar Z (2007) ROS, mitochondria and the regulation of autophagy. Trends Cell Biol 17, 422-427.

[121] Kirkland RA, Adibhatla RM, Hatcher JF, Franklin JL (2002) Loss of cardiolipin and mitochondria during programmed 
neuronal death: evidence of a role for lipid peroxidation and autophagy. Neuroscience 115, 587-602.

[122] Cheung EC, Joza N, Steenaart NA, McClellan KA, Neuspiel M, McNamara S, MacLaurin JG, Rippstein P, Park DS, Shore GC, McBride HM, Penninger JM, Slack RS (2006) Dissociating the dual roles of apoptosis-inducing factor in maintaining mitochondrial structure and apoptosis. EMBO J 25, 4061-4073.

[123] Cregan SP, Fortin A, MacLaurin JG, Callaghan SM, Cecconi F, Yu SW, Dawson TM, Dawson VL, Park DS, Kroemer G, Slack RS (2002) Apoptosis-inducing factor is involved in the regulation of caspase-independent neuronal cell death. $J$ Cell Biol 158, 507-517.

[124] Klein JA, Longo-Guess CM, Rossmann MP, Seburn KL, Hurd RE, Frankel WN, Bronson RT, Ackerman SL (2002) The harlequin mouse mutation downregulates apoptosisinducing factor. Nature 419, 367-374.

[125] Beckman J, Beckman T, Chen J, Marshall P, Freeman B (1990) Apparent hydroxyl radical production by peroxynitrite: implications for endothelial injury from nitric oxide and superoxide. Proc Natl Acad Sci U S A 87, 1620-1624.

[126] Vignais P (2002) The superoxide-generating NADPH oxidase: structural aspects and activation mechanism. Cell Mol Life Sci 59, 1428-1459.

[127] Halliwell B, Gutteridge J (1999) Free Radicals in Biology and Medicine, Oxford University Press, Oxford

[128] Babior BM (2000) Phagocytes and oxidative stress. Am J Med 109, 33-44.

[129] Hussien M, Delecata RJ, Carey PD (2002) Neutrophil hypochlorous acid production is impaired in multiple organ failure patients with candidaemia; reversal with antifungal agents. Inflamm Res 51, 213-217.

[130] King CC, Jefferson MM, Thomas EL (1997) Secretion and inactivation of myeloperoxidase by isolated neutrophils. $J$ Leukoc Biol 61, 293-302.

[131] Eiserich J, Cross C, Jones A, Halliwell B, Vliet Avd (1996) Formation of nitrating and chlorinating species by reaction of nitrite with hypochlorous acid. A novel mechanism for nitric oxide-mediated protein modification. J Biol Chem $\mathbf{2 7 1}$, 19199-19208.

[132] Guix F, Uribesalgo I, Coma M, Munoz F (2005) The physiology and pathophysiology of nitric oxide in the brain. Prog Neurobiol 76, 126-152.

[133] Iadecola C, Zhang F, Xu S, Casey R, Ross M (1995) Inducible nitric oxide synthase gene expression in brain following cerebral ischemia. J Cereb Blood Flow Metab 15, 378-384.

[134] Beckman J, Koppenol W (1996) Nitric oxide, superoxide, and peroxynitrite: the good, the bad, and ugly. Am J Physiol 271, C1424-C1437.

[135] Brown G (1999) Nitric oxide and mitochondrial respiration. Biochim Biophys Acta 1411, 351-369.

[136] Chinopoulos C, Adam-Vizi V (2006) Calcium, mitochondria and oxidative stress in neuronal pathology. Novel aspects of an enduring theme. FEBS J 273, 433-450.

[137] McMahon M, Itoh K, Yamamoto M, Chanas S, Henderson C, McLellan L, Wolf C, Cavin C, Hayes J (2001) The Cap'n'Collar basic leucine zipper transcription factor Nrf2 (NF-E2 p45-related factor 2) controls both constitutive and inducible expression of intestinal detoxification and glutathione biosynthetic enzymes. Cancer Res 61, 3299-3307.

[138] Johnson J, Johnson D, Kraft A, Calkins M, Jakel R, Vargas M, Chen P (2008) The Nrf2 - ARE pathway: an indicator and modulator of oxidative stress in neurodegeneration. Ann N Y Acad Sci 1147, 61-69.

139] Zhao J, Moore AN, Redell JB, Dash PK (2007) Enhancing expression of Nrf2-driven genes protects the blood brain barrier after brain injury. J Neurosci 27, 10240-10248.

[140] Kaspar JW, Niture SK, Jaiswal AK (2009) Nrf2:INrf2 (Keap1) signaling in oxidative stress. Free Radic Biol Med 47, 1304-1309.

[141] Wilce MC, Parker MW (1994) Structure and function of glutathione S-transferases. Biochim Biophys Acta 1205, 1-18.

[142] Faig M, Bianchet MA, Talalay P, Chen S, Winski S, Ross D, Amzel LM (2000) Structures of recombinant human and mouse $\mathrm{NAD}(\mathrm{P}) \mathrm{H}$ :quinone oxidoreductases: species comparison and structural changes with substrate binding and release. Proc Natl Acad Sci U S A 97, 3177-3182.

[143] Liu ZJ, Sun YJ, Rose J, Chung YJ, Hsiao CD, Chang WR, Kuo I, Perozich J, Lindahl R, Hempel J, Wang BC (1997) The first structure of an aldehyde dehydrogenase reveals novel interactions between NAD and the Rossmann fold. Nat Struct Biol 4, 317-326.

[144] Wasserman W, Fahl W (1997) Comprehensive analysis of proteins which interact with the antioxidant responsive element: correlation of ARE-BP-1 with the chemoprotective induction response. Arch Biochem Biophys 344, 387-396.

[145] Gorlach A, Klappa P, Kietzmann T (2006) The endoplasmic reticulum: folding, calcium homeostasis, signaling, and redox control. Antioxid Redox Signal 8, 1391-1418.

[146] Schröder M (2008) Endoplasmic reticulum stress responses. Cell Mol Life Sci 65, 862-894.

[147] Harding H, Zhang Y, Ron D (1999) Protein translation and folding are coupled by an endoplasmic-reticulum-resident kinase. Nature 397, 271-274.

[148] Sanden MVD, Houweling M, Golde Lv, Vaandrager A (2003) Inhibition of phosphatidylcholine synthesis induces expression of the endoplasmic reticulum stress and apoptosis-related protein CCAAT/enhancer-binding proteinhomologous protein (CHOP/GADD153). Biochem J 369, 643-650.

[149] Wang K (2000) Calpain and caspase: can you tell the difference? Trends Neurosci 23, 20-26.

[150] Schröder M, Kaufman R (2005) ER stress and the unfolded protein response. Mutat Res 569, 29-63.

[151] Gaczynska M, Osmulski P, Ward W (2001) Caretaker or undertaker? The role of the proteasome in aging. Mech Ageing Dev 122, 235-254.

[152] Mandel S, Grunblatt E, Riederer P, Amariglio N, JacobHirsch J, Rechavi G, Youdim M (2005) Gene expression profiling of sporadic Parkinson's disease substantia nigra pars compacta reveals impairment of ubiquitin-proteasome subunits, SKP1A, aldehyde dehydrogenase, and chaperone HSC-70. Ann N Y Acad Sci 1053, 356-375.

[153] Yew E, Cheung N, Choy M, Qi R, Lee A, Peng Z, Melendez A, Manikandan J, Koay E, Chiu L, Ng W, Whiteman M, Kandiah J, Halliwell B (2005) Proteasome inhibition by lactacystin in primary cortical neuronal cells induces both potentially neuroprotective and proapoptotic transcriptional responses: a microarray analysis. J Neurochem 94, 943-956.

[154] Santo-Domingo J, Demaurex N (2010) Calcium uptake mechanisms of mitochondria. Biochim Biophys Acta, in press.

[155] Crocker S, Smith P, Jackson-Lewis V, Lamba W, Hayley S, Grimm E, Callaghan S, Slack R, Melloni E, Przedborski S, Robertson G, Anisman H, Merali Z, Park D (2003) Inhibition of calpains prevents neuronal and behavioral deficits in an 
MPTP mouse model of Parkinson's disease. J Neurosci 23, 4081-4091.

[156] Donato R (2001) S100: a multigenic family of calciummodulated proteins of the EF-hand type with intracellular and extracellular functional roles. Int J Biochem Cell Biol 33 637-668.

[157] Chen M, Yap Y, Choy M, Koh C, Seet S, Duan W, Whiteman M, Cheung N (2006) Early induction of calpains in rotenonemediated neuronal apoptosis. Neurosci Lett 397, 69-73.

[158] Peng Z, Chen M, Yap Y, Manikandan J, Melendez A, Choy M, Moore P, Cheung N (2008) Proteasome inhibition: an early or late event in nitric oxide-induced neuronal death? Nitric Oxide 18, 136-145.

[159] Yap Y, Whiteman M, Bay B, Li Y, Sheu F, Qi R, Tan C, Cheung N (2006) Hypochlorous acid induces apoptosis of cultured cortical neurons through activation of calpains and rupture of lysosomes. J Neurochem 98, 1597-1609.

[160] Chua B, Guo K, Li P (2000) Direct cleavage by the calcium- activated protease calpain can lead to inactivation of caspases. J Biol Chem 275, 5131-5135.

[161] Murphy MP, Smith RA (2007) Targeting antioxidants to mitochondria by conjugation to lipophilic cations. Annu Rev Pharmacol Toxicol 47, 629-656.

[162] Szeto HH (2008) Mitochondria-targeted cytoprotective peptides for ischemia-reperfusion injury. Antioxid Redox Signal 10, 601-619.

[163] Dennis GJ, Sherman B, Hosack D, Yang J, Gao W, Lane H, Lempicki R (2003) DAVID: Database for Annotation, Visualization, and Integrated Discovery. Genome Biol 4, P3.

[164] Huang D, Sherman B, Lempicki R (2009) Systematic and integrative analysis of large gene lists using DAVID Bioinformatics Resources. Nature Protoc 4, 44-57.

[165] Carroll FY, Beart PM, Cheung NS (1996) NMDA-mediated activation of the NO/cGMP pathway: characteristics and regulation in cultured neocortical neurones. J Neurosci Res 43, 623-631. 